Research Article

\title{
Statistical Modelling to Study the Implications of Coated Tools for Machining AA 2014 Using Grey Taguchi-Based Response Surface Methodology
}

\author{
Madhanagopal Manoharan, ${ }^{1}$ Arul Kulandaivel, ${ }^{2}$ Adinarayanan Arunagiri, ${ }^{3}$ \\ Mohamad Reda A. Refaai, ${ }^{4}$ Simon Yishak $\mathbb{D}^{5}{ }^{\mathbf{5}}$ and Gowthaman Buddharsamy ${ }^{6}$ \\ ${ }^{1}$ Department of Mechanical Engineering, Indian Institute of Information Technology, Design and Manufacturing, \\ Kancheepuram, Chennai 600127, India \\ ${ }^{2}$ Department of Mechanical Engineering, Agni College of Technology, Thalambur, Chennai 600130, India \\ ${ }^{3}$ Department of Mechanical Engineering, AMET University, Kanathur, Chennai 603112, India \\ ${ }^{4}$ Prince Sattam bin Abdulaziz University, College of Engineering, Department of Mechanical Engineering, Alkharj 16273, \\ Saudi Arabia \\ ${ }^{5}$ College of Engineering and Argo-Industrial Technology, Sawla Campus, Arba Minch University, Addis Ababa, Ethiopia \\ ${ }^{6}$ Department of Mechanical Engineering, Kings Engineering College, Sriperumbudur, Chennai 602117, India
}

Correspondence should be addressed to Simon Yishak; simon.yishak@amu.edu.et

Received 4 October 2021; Accepted 2 November 2021; Published 30 November 2021

Academic Editor: P Ganeshan

Copyright () 2021 Madhanagopal Manoharan et al. This is an open access article distributed under the Creative Commons Attribution License, which permits unrestricted use, distribution, and reproduction in any medium, provided the original work is properly cited.

\begin{abstract}
Milling is the surface machining process by removing material from the raw stock using revolving cutters. This process accounts for a major stake in most of the Original Equipment Manufacturing (OEM) industries. This paper discusses optimizing process parameters for machining the AA 2014 T 651 using a vertical milling machine with coated cutting tools. The process parameters such as cutting speed, depth of cut, and type of the cutting tool with all its levels are identified from the previous literature study and several trial experiments. The Taguchi $L_{9}$ Orthogonal Array (OA) is used for the experimental order with the chosen input parameters. The commonly used cutting tools in the machining industry, such as High-Speed Steel (HSS) and its coated tools, are considered in this study. These tools are coated with Titanium Nitride (TiN) and Titanium Aluminum Nitride (TiAlN) by Physical Vapor Deposition (PVD) technique. The output responses such as cutting forces along the three-axis are measured using a milling tool dynamometer for the corresponding input factors. The input process parameters are optimized by considering the output responses such as MRR, machining torque, and thrust force. Grey Taguchi-based Response Surface Methodology (GTRSM) is used for multiobjective multiresponse optimization problems to find the optimum input process parameter combination for the desired response. Polynomial regression equations are generated to understand the mathematical relation between the input factor and output responses as well as Grey Relational Grade (GRG) values. The optimum process parameter combination from the desirability analysis is the HSS tool coated with TiAlN at a cutting speed of $270 \mathrm{rpm}$ and a depth of cut value of $0.2 \mathrm{~mm}$.
\end{abstract}

\section{Introduction}

Modern-day cutting tools used in the machining industry can be coated with combination of alloying elements, which provides a wide range of advantages in improving the tool life. These coated tools may reduce the manufacturing cost, and thereby the cost of the manufactured part is significantly reduced. The majority of modern machining is done using computer numerical control (CNC), which allows computers to control mills, lathes, and other cutting machines. Milling is a type of machining that removes material from a work piece by advancing rotary cutters in a direction that is at an angle to the tool's axis. From small individual pieces to huge, heavy-duty group milling processes, it encompasses a 
wide range of procedures and machinery. It is one of the most widely utilized procedures for machining parts with sufficient precision and tolerance control in industry and machine shops today.

Milling operations performed using different milling cutters may be grouped as peripheral milling and face milling. The action of a milling cutter to generate a machined surface parallel to the cutter's axis is known as peripheral milling. This sort of milling is considered for study in this work. Commonly used milling cutters include end mill, ball nose cutter, slab mill, side and face cutter, hob, thread mill, face cutter, fly cutter, woodruff cutter, and hollow mill. Materials used in those cutters include High-Speed Steel (HSS), cemented carbides, tool steels, cast-tool material, plain carbon tool steel, and stellite. High-Speed Steel (HSS) mill tool is utilized in this work, which is widely used by several manufacturing industries for affordable metal cutting operations.

The coatings applicable for the HSS end mill cutter are Titanium Nitride (TiN), Titanium Aluminum Nitride (TiAlN), Titanium Carbo-Nitride (TiCN), Zirconium Nitride $(\mathrm{ZrN})$, Diamond, and Black Oxide. TiN and TiAlN coating are used in this research to coat the HSS tool in these available coatings. Usually, these coatings can be provided on the cutting tool using Physical Vapor Deposition (PVD) or Chemical Vapor Deposition (CVD) techniques. In general, PVD coating is a cost-effective solution for sputtering applications. Hence, the PVD technique is used for coating the HSS tool cutters in this work. The TiN coating increases the hardness of the HSS cutting tool and can withstand higher oxidation temperature, while TiAlN coating provides more surface hardened tool than TiN. It is because of the presence of $\mathrm{Al}$ and $\mathrm{Ti}$ compositions. This TiAlN coated tool is a viable alternate option for high-speed machining and high-temperature machining applications. The formation of the aluminum oxide layer provides better tool life for high heat applications.

Aluminum Alloys are widely used in engineering structures, because they are of lightweight and better corrosion resistance [1]. The most common alloying elements for Aluminum Alloys is Copper $(\mathrm{Cu})$, Magnesium $(\mathrm{Mg})$, Manganese (Mn), Silicon (Si), Tin (Sn), and Zinc (Zn). Aluminum Alloy is the material of choice for several engineering applications, which has good aesthetic and high strength properties. These Aluminum alloys are available in several series such as $1 \mathrm{xxx}, 2 \mathrm{xxx}, 3 \mathrm{xxx}, 4 \mathrm{xxx}, 5 \mathrm{xxx}, 6 \mathrm{xxx}$, and $7 \mathrm{xxx}$ series. This work uses AA 2014 as a working material for the milling process. AA 2014 is an Aluminum-Copperbased alloy widely used in aerospace, defense, and naval engineering applications. This AA 2014 is difficult to machine at particular tempers and has high strength next to Aluminum-Zinc alloys.

This work involves multiple input parameters and multiple-output responses. Some of the commonly applied methods for multiresponse optimization are Grey Relational Analysis (GRA), Artificial Neural Network (ANN), Convolutional Neural Network (CNN), Fuzzy logic, Principal Component Analysis (PCA), Simulated Annealing (SA), Bio-inspired algorithms, and Nelder-Mead Simplex method
[2]. This sort of optimization study is used by researchers in various domains ranging from Civil Engineering [3] to advanced Additive Manufacturing techniques [4].

Recently, multiresponse optimization is a major interest for industries and academicians to find the optimum process parameters. Maiyar et al. used Grey Relational Analysis to explore the parameter optimization of end milling operation for Inconel 718 superalloy [5] using multiresponse criteria based on Taguchi L9 Orthogonal Array. The input parameters such as cutting speed, feed rate, and depth of cut are optimized by considering multiple output responses such as average surface roughness $\left(R_{a}\right)$ and Material Removal Rate. Cutting velocity $(75 \mathrm{~m} / \mathrm{min})$, feed rate $(0.06 \mathrm{~mm} /$ tooth $)$, and depth of cut were identified to be the best cutting parameters combination for machining by the authors $(0.4 \mathrm{~mm})$. The authors also observed that the Material Removal Rate (MRR) is increased by $64.8 \%$, and surface roughness is decreased by 9.52\%. Grey Relational Grade obtained is used for Analysis of Variance (ANOVA) calculations. Das et al. used an improved optimization approach by combining Taguchi $L_{25}$ Orthogonal Array design and Grey-Fuzzy logic technique for optimizing machining parameters of the CNC milling of $\mathrm{Al}-4.5 \% \mathrm{Cu}-\mathrm{TiC}$ Metal Matrix Composites [6]. The optimum process parameter combination found in this study has a cutting speed $(600 \mathrm{rpm})$, feed $(40 \mathrm{~mm} / \mathrm{min})$, and depth of cut $(0.30 \mathrm{~mm})$ by considering the output responses such as cutting force $\left(F_{c}\right)$, average surface roughness $\left(R_{a}\right)$, and an average maximum height of the profile $\left(R_{z}\right)$. The optimum process parameter combination has a high grey fuzzy reasoning grade (0.8191). Durakbasa et al. extended further study of the effect of coating on the tool and found that the coating in the cutting tool is the predominant factor affecting the surface quality of the machined parts [7]. The authors have coated the carbide tools with AlTiN, TiAlN, and $\mathrm{ZrN}$ to study the cutting parameter implications on machining AISI $\mathrm{H} 13$ hot work steel. Taguchi $L_{27}$ Orthogonal Array is used to study the relationship between the input process parameter and output responses. Cutting tool tip radius and coating type are the significant input process parameters affecting the average surface roughness $\left(R_{a}\right)$ of the machined surface besides feed rate, depth of cut, and cutting speed. Lu et al. used a hybrid approach by coupling the performance index Grey Relational Grade (GRG) with Principal Component Analysis (PCA). On the rough cutting of SKD61 tool steel, the authors discovered the optimal combination of cutting parameters such as milling type, spindle speed, feed per tooth, radial depth of cut, and axial depth of cut for highspeed end milling [8]. For high-speed milling of SKD61 tool steel, the down milling procedure with a spindle speed of $12000 \mathrm{rpm}$, feed rate of $0.04 \mathrm{~mm} /$ tooth, axial depth of cut $(0.8 \mathrm{~mm})$, and radial depth of cut $(1 \mathrm{~mm})$ is regarded the ideal cutting parameter combination.

The Response Surface Methodology (RSM) was used by Elsen et al. to study the end milling process parameters for multiobjective optimization [9]. The authors used stir cast Alumina reinforced Aluminum Metal Matrix Composites (AAMMC) and found that the cutting speed $(1750 \mathrm{rev} / \mathrm{min})$, feed rate $(0.3 \mathrm{~mm} / \mathrm{rev})$, and depth of cut $(0.2 \mathrm{~mm})$ are the optimum parameters for end milling operations. Shaik and 
Srinivas used the neural network-based RSM to find the optimum process parameter combination [10] for end milling operations in AA-6061 work material using a multiobjective approach. The authors found that the cutting speed of $1800.954 \mathrm{rpm}$, feed rate of $41.826 \mathrm{~mm} / \mathrm{min}$, and axial depth of $0.799 \mathrm{~mm}$ are the optimum combination for machining the AA-6061 material. Ren et al. presented a multiobjective optimization problem [11] using the Taguchi method for experimental design and Grey Relational Analysis to obtain the optimum process parameter combination in the end milling Ti-5Al-5Mo-5V-1Cr-1Fe titanium alloy. The authors considered multiresponse such as cutting forces, surface roughness, and acceleration on various tools with varying tool geometry. They found that the fluting rake angle of $4^{\circ}$, gash angle of $35^{\circ}$ helix angle of $45^{\circ}$, gash rake angle of $2^{\circ}$, and pitch angle difference of $4^{\circ}$ are the optimal controllable factors in the study. Adalarasan et al. considered the Taguchi $L_{18}$ Orthogonal Array for designing the experimental order and extended RSM by using a hybrid approach such as Grey Taguchi based Response Surface Methodology (GT-RSM) for optimizing the process parameters [12]. The authors optimized the plasma arc cutting parameters such as arc current, torch stand-off, cutting speed, and gas pressure by considering the responses such as surface roughness and kerf width. The authors proposed that the optimized results provide better desirability for finding the optimum process parameters using GRG values. Similar multiobjective optimization to study the milling parameters for machining Ultrahigh-Strength Steel was introduced by $\mathrm{Xu}$ et al. using RSM equations. The authors used a Paretooptimal solution to obtain the optimum process parameter combination using Non-Dominated Sorting Genetic Algorithm-II (NDSGA-II). The authors mentioned that the RSM could not deal with the multiresponse problem [13], and this sort of multiobjective optimization provides optimum process parameter combination. According to the literature review, more research into the influence of coated tools on milling AA 2014 is needed, taking into account the Material Removal Rate (MRR) and the impact of cutting pressures during the material removal process. As a result, the quality of the milled surface is explored experimentally in this paper in order to discover a relationship between the range of forces and Material Removal Rate (MRR) for the appropriate input process parameters.

\section{Materials and Methods}

Grey Relational Analysis provides a better solution for multiresponse optimization problems [14]. Engineering judgement, assignment of weight, Regression analysis, data envelopment based Ranking approach, fuzzy multiple attribute decision making, fuzzy logic, Grey Relational Analysis, Artificial Neural Networks, goal-programming approach, and desirability function analysis are the available methods for multiobjective multiresponse problems [15]. In this study, Grey Taguchi-based Response Surface Methodology (GT-RSM) is used to analyze the factor-response relationship. The full factorial Taguchi $L_{9}$ Orthogonal Array experimental design is selected to conduct the experiment in an organized manner. In the current study, the operating cutting speed considered in this study ranges from 90 to $450 \mathrm{rpm}$. The depth of cut varies from $0.2 \mathrm{~mm}$ to $0.6 \mathrm{~mm}$, while the feed rate is kept constant at $40 \mathrm{~mm} / \mathrm{min}$. The work material is the Aluminum Alloy AA 2014 T 651 condition, a heat-treated solution, stress relieved by elongation, and artificial ageing. The chemical composition test is performed to confirm the presence of alloying in the right proportions and hardness tests to study the characteristics of the alloy. In addition, microstructural studies are carried out to visualize the AA 2014 microstructure using Optical Microscope. The cutting forces in three dimensions are measured using strain sensors placed on the work piece holding fixture using Milling Tool Dynamometer.

2.1. Material Selection. Aluminum Alloy AA 2014 can be easily machinable at a specific temperature, and it is one of the strongest available Aluminum Alloys with high hardness and better tensile properties. The density value of the chosen AA 2014 is $2.8 \mathrm{gm} / \mathrm{cm}^{3}$.

2.1.1. Microstructure Characterisation. The AA 2014 specimens are polished using Silicon Carbide abrasive papers of various grid sizes (200\#, 400\#, 600\#, 800\#, 1000\#, and 1200\#) before microstructure characterization is shown in Figure 1. These specimens are then subjected to cloth polish using a diamond abrasive size $0.5 \mu \mathrm{m}-1 \mu \mathrm{m}$ to obtain mirror polish. The polished specimen surface is etched with Keller's reagent [16] of composition $\left(1 \% \mathrm{HF}+1.5 \% \mathrm{HCl}+2.5 \% \mathrm{HNO}_{3}+95 \%\right.$ water). The surface has dispersed dots of particles (mostly copper), which shows a uniform distribution of alloying elements.

In addition to this microstructure analysis, chemical composition and hardness tests are also performed to examine the material property characteristics. The results are discussed in the upcoming sections.

2.1.2. Chemical Composition Analysis. The chemical composition test results of the purchased material are provided in Table 1. Copper is the primary alloying element in the AA 2XXX series.

Since there is a presence of 3.9 to $5 \%$ copper in this particular material, this indicates that it is Aluminum Alloy AA 2014 [17]. The purchased material is strengthened to get T651 condition by solution heat-treated, stress-relieved by stretching, and artificial ageing in controlled environmental conditions [18].

2.1.3. Hardness Test. The hardness of the AA 2014 material subjected to machining is tested using Brinell Hardness testing machine and Vickers microhardness tester.

(1) Brinell Hardness Test. The hardness of the AA 2014 work material is tested at various loads ranging from $1 \mathrm{~kg}$ to $3 \mathrm{~kg}$ using the Brinell scale, which is provided in Table 2. The details of the load application, diameter of impression, and specimen surface area are presented. 


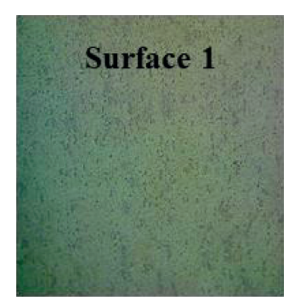

(a)

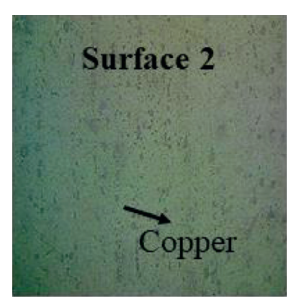

(b)

Figure 1: Microstructure of the chosen AA 2014 (black dots represent copper).

Table 1: Percentage of elements distribution in the chosen AA 2014 material.

\begin{tabular}{lccccccccc}
\hline Type of element & $\mathrm{Cr}(\%)$ & $\mathrm{Cu}$ & $\mathrm{Fe}(\%)$ & $\mathrm{Mg}$ & $\mathrm{Mn}$ & $\mathrm{Si}$ & $\mathrm{Ti}(\%)$ & $\mathrm{Zn}(\%)$ & $\mathrm{Al}$ \\
\hline \% contribution & 0.1 & $3.9 \%-5 \%$ & 0.7 & $0.2 \%-0.8 \%$ & $0.4 \%-1.2 \%$ & $0.5 \%-1.2 \%$ & 0.15 & 0.25 & $\mathrm{Rest}$ \\
\hline
\end{tabular}

TABLE 2: Brinell hardness test on AA 2014 material.

\begin{tabular}{|c|c|c|c|c|c|}
\hline \multirow[t]{2}{*}{ Trial no. } & \multirow[t]{2}{*}{ Applied load (gm) } & \multicolumn{2}{|c|}{$\begin{array}{c}\text { Diameter of } \\
\text { impression }(\mathrm{mm})\end{array}$} & \multirow[t]{2}{*}{ Specimen surface area $\left(\mathrm{mm}^{2}\right)$} & \multirow[t]{2}{*}{ BHN } \\
\hline & & $D$ & $d$ & & \\
\hline 1 & 1000 & 10 & 3.2 & 8.26 & 121.06 \\
\hline 2 & 2000 & 10 & 4.3 & 15.26 & 131.06 \\
\hline 3 & 3000 & 10 & 5.0 & 21.04 & 142.58 \\
\hline
\end{tabular}

In addition, a sample calculation is provided below to find $\mathrm{BHN}$.

$$
\text { Brinell Hardness Number }(\mathrm{BHN})=\frac{F}{A_{s}},
$$

where $A_{s}=\pi D\left(D-\sqrt{D^{2}-d^{2}}\right) / 2$

The specimen surface area for the first trial is $A_{s}=\pi * 10\left(10-\sqrt{10^{2}-3.2^{2}}\right) / 2$, where the value of specimen surface area is $8.26 \mathrm{~mm}^{2}$. The BHN is the ratio of load applied to the calculated specimen surface area. The value of $\mathrm{BHN}$ for the first set is found to be 121.06 .

(2) Vickers Microhardness Test. The Vickers microhardness test employs a square-shaped pyramid diamond indenter with a vertex angle of $136^{\circ}$, which is driven into the surface of the selected AA 2014 material at a predefined force, $F$. The initial application of force takes 2 to 8 seconds, and the force is sustained for 10 to 15 seconds during the test. The diagonal indentation lengths are measured when the applied force is removed to get the Vickers Hardness Number (VHN) with $1 \mathrm{~N}$ application of force [19]. In the chosen AA 2014, the VHN on the Vickers scale is 158,155 , and 154.

2.2. Tool Selection. High-Speed Steel (HSS) tools are commonly used in medium scale and small scale industries. This affordable HSS tool can withstand more cutting force and better tool life compared to carbide tools. HSS material is widely used in various segments in the manufacturing industry as drill bits, reamer tools, side and face mill cutters, slab mills, end mills, and straddles milling cutters. In the current work, High-Speed Steel (HSS) tool and the HSS tool with coatings are used to study the milling operations.
Table 3 shows the specifications of the HSS tool used in this study.

The manufacturer of the HSS mill tool is Sandvik Coromant, which is supplied by ProSol, Ambattur, Chennai, India. This HSS tool is highly suitable for intermittent cutting applications.

2.3. Coating Method. The tool's surface hardness will be increased by using coatings. These coatings will improve tool life and be enabled for faster cutting speeds and feeds [20]. This work uses two coating materials: Titanium Nitride (TiN) and Titanium Aluminum Nitride (TiAlN). The coating on the HSS tool was done at Oerlikon friction systems (India) Private Limited, Irungattukottai, Chennai, India. The coating of these tools is done based on the sputtering principle using the PVD technique.

\section{Experimental Details and Data Analysis}

All the experiments in this study are conducted in the vertical milling machine supplied by S. M. Engineering works, Punjab, India, shown in Figure 2. The HSS end mill tool with and without coating is used to machine the AA 2014 by performing experiments as per the experimental order in this machine.

The cutting forces acting in three dimensions are measured using Milling Tool Dynamometer (M/S Tamilnadu Engineering Instruments, Chennai, India). This device has four arms bounding strain gauge component bridge sensors to measure the three-dimensional axis forces. Three readings for each set of forces are calculated at the start of the cutting operation, half the cutting toolpath length, and near the end of the milling operation. The average of the three 
TABLe 3: Tool description of the HSS mill tool.

\begin{tabular}{lcc}
\hline Type of cutter & End mill cutter \\
\hline $\begin{array}{l}\text { Diameter of the cutting tool } \\
\text { Length of the cutting tool }\end{array}$ & $10 \mathrm{~mm}$ \\
$\begin{array}{l}\text { Flute length } \\
\text { Number of flutes }\end{array}$ & $100 \mathrm{~mm}$ \\
& Type of cutting tool & 4 \\
& & \\
\hline & HSS tool - TiN coated (HSST-TiN) & HSS tool - TiAlN coated (HSST-TiAlN) \\
\hline
\end{tabular}

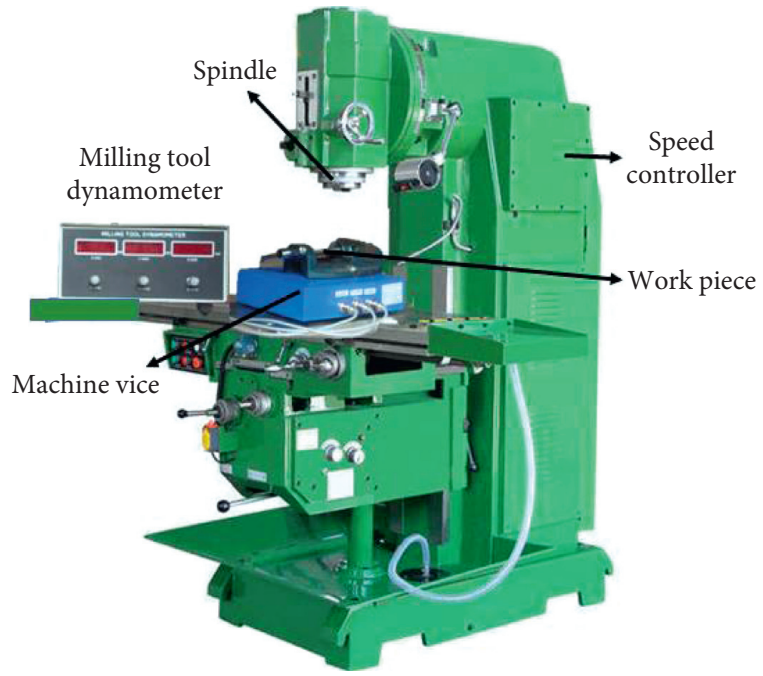

FiguRE 2: Vertical machining center used for experimentation in this research work.

readings for each measured force is used to calculate Torque and thrust force. Machining is carried out at various process parameter settings mentioned in Table 4 . The notations of the end mill cutter tools are the High-Speed Steel tool (HSST), High-Speed Steel tool coated with Titanium Nitride (HSST-TiN) tool, and High-Speed Steel tool coated with Titanium Aluminum Nitride (HSST-TiAlN).

Several factors affect the production rate in the manufacturing industry. The major factors such as cutting speed, feed rate, and depth of cut are the predominant process parameters in any machining industry [21]. This study provides the influence of tool coating on the output responses such as Torque, thrust force, and Material Removal Rate. For improved visualization, response surface and contour graphs are supplied, which are also utilized to appropriately identify the input process parameters for the required output response.

3.1. Input Process Parameters and Their Levels. The number of experiments to identify the relationship between the input parameters and output responses is significantly reduced by implementing the Taguchi Orthogonal Array technique [22]. In this work, $L_{9}\left(3^{3}\right)$ Orthogonal Array design shown in Table 5 is used to find the influence of the input factors over the measured responses.
TABLE 4: Input parameters and their levels.

\begin{tabular}{lccc}
\hline Input parameters & Level 1 & Level 2 & Level 3 \\
\hline Cutting speed (rpm) & 90 & 270 & 450 \\
Depth of cut (mm) & 0.2 & 0.4 & 0.6 \\
Type of cutting tool & HSST & HSST-TiN & HSST-TiAlN \\
\hline
\end{tabular}

TABLE 5: $L_{9}$ Orthogonal array for fitting the input process parameters.

\begin{tabular}{lccc}
\hline $\begin{array}{l}\text { Experimental } \\
\text { order }\end{array}$ & $\begin{array}{c}\text { Cutting speed } \\
(\mathrm{rpm})\end{array}$ & $\begin{array}{c}\text { Depth of cut } \\
(\mathrm{mm})\end{array}$ & Type of cutting tool \\
\hline 1 & 90 & 0.2 & HSST-TiAlN \\
2 & 90 & 0.4 & HSST \\
3 & 90 & 0.6 & HSST-TiN \\
4 & 270 & 0.2 & HSST \\
5 & 270 & 0.4 & HSST-TiN \\
6 & 270 & 0.6 & HSST-TiAlN \\
7 & 450 & 0.2 & HSST-TiN \\
8 & 450 & 0.4 & HSST-TiAlN \\
9 & 450 & 0.6 & HSST \\
\hline
\end{tabular}

The experimental machining is done on the AA 2014 material using individual blocks for each set as per the orthogonal array design. Figure 3 shows the images of the machined work pieces as per the experimental order.

All the work piece material used in this study has a standard size of $60 \mathrm{~mm} \times 60 \mathrm{~mm} \times 30 \mathrm{~mm}$. The mill tool plunges in the work piece and performs machining for a length of $40 \mathrm{~mm}$.

3.2. Output Measured Parameters. The Torque and MRR are calculated using the following measured forces and machining time in Table 6 , where $T_{m}$ represents the actual machining time.

A mill tool dynamometer is used to measure the forces operating on the work piece, and the machining time for each input process parameter combination is recorded.

\section{Results and Discussion}

The output response parameters considered in this study are the thrust force, Material Removal Rate (MRR), and Torque. Machining Torque is calculated with the help of cutting force and diameter of the tool, and Metal Removal Rate is calculated using the volume of material removed and 


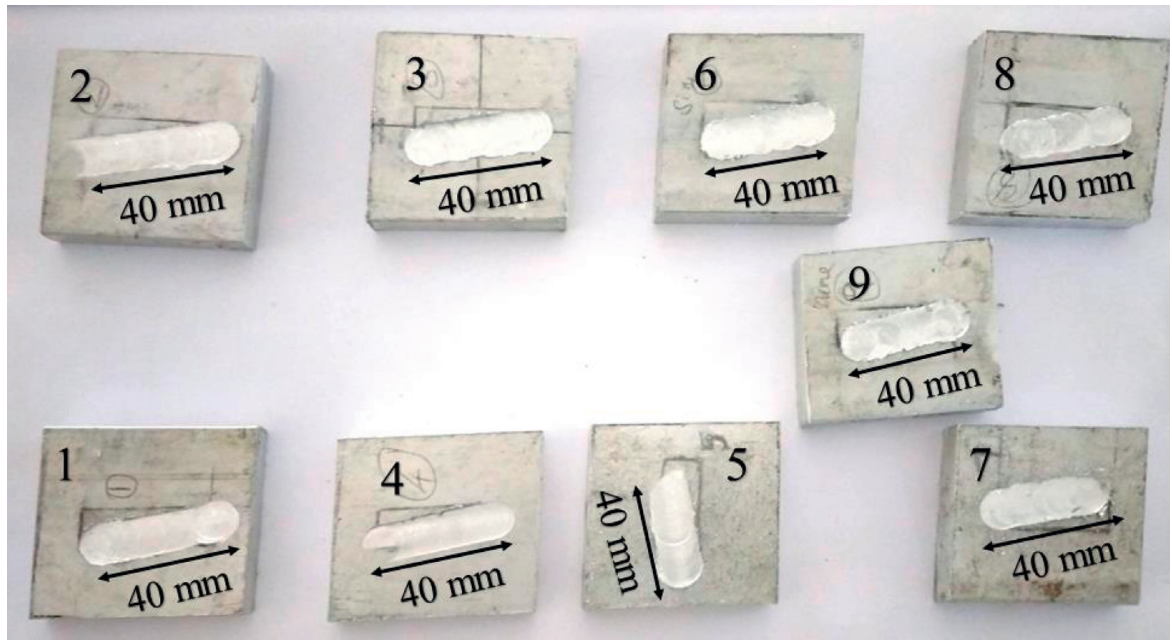

FIGURE 3: Machined work pieces of AA 2014 material.

TABle 6: Measured response for the corresponding input process parameter set.

\begin{tabular}{|c|c|c|c|c|c|c|c|}
\hline Exp. order & Cutting speed (rpm) & Depth of cut $(\mathrm{mm})$ & Type of cutting tool & $F_{x}(\mathrm{~N})$ & $F_{y}(\mathrm{~N})$ & $F_{z}(\mathrm{~N})$ & $T_{m}(\mathrm{sec})$ \\
\hline 1 & 90 & 0.2 & HSST-TiAlN & 78.48 & 93.2 & 117.72 & 127 \\
\hline 2 & 90 & 0.4 & HSST & 58.86 & 78.48 & 78.48 & 165 \\
\hline 3 & 90 & 0.6 & HSST-TiN & 73.58 & 103.005 & 88.29 & 151 \\
\hline 4 & 270 & 0.2 & HSST & 68.67 & 88.29 & 39.24 & 98 \\
\hline 5 & 270 & 0.4 & HSST-TiN & 83.39 & 78.48 & 125.57 & 82 \\
\hline 6 & 270 & 0.6 & HSST-TiAlN & 88.29 & 122.63 & 78.48 & 56 \\
\hline 7 & 450 & 0.2 & HSST-TiN & 107.91 & 117.72 & 103 & 43 \\
\hline 8 & 450 & 0.4 & HSST-TiAlN & 117.72 & 176.58 & 264.87 & 38 \\
\hline 9 & 450 & 0.6 & HSST & 80.44 & 127.53 & 147.15 & 45 \\
\hline
\end{tabular}

machining time. For torque calculation, the following equation is used for the experimental order combination:

$$
\text { Torque }(\mathrm{Nm})=\frac{\text { Cutting force }(\mathrm{N}) \times \text { Dia. of mill tool }(\mathrm{mm})}{2000} \text {. }
$$

MRR is calculated by comparing the starting weight of the work piece before to machining with the final weight of the work piece after the material has been removed. Equation (3) provides the information to calculate the material removal rate in this experimental study:

$$
\operatorname{MRR}\left(\frac{\mathrm{mm}^{3}}{\mathrm{~s}}\right)=\frac{(\text { Initial weight of workpiece }(\mathrm{gm})-\text { Final weight of workpiece }(\mathrm{gm}))}{\operatorname{Density}\left(\mathrm{gm} / \mathrm{mm}^{3}\right) \times \operatorname{Machining} \text { time }(\mathrm{sec})} .
$$

The calculated MRR, torque, and thrust force are given in Table 7. These responses are used for the input for the Grey Relational Analysis.

To find the mathematical models link between the input process parameters and output response, second-order polynomial regression equations are produced. These equations are used to generate the response and contour plot for better visualization of the response-process parameter relationship and predict the proper set of the process parameter combination. All the regression analyses in this study are analyzed using Minitab software. The 3D response and $2 \mathrm{D}$ contour are plotted using MATLAB software from the equations obtained from regression analysis.

4.1. Second-Order Polynomial Regression Analysis for MRR. The second-order polynomial regression equation is generated for the MRR by varying the process factors such as cutting speed, cutting tool type, and depth of cut. In addition to these factors, several other process parameters affect the MRR, torque, and thrust force. It may differ by material, machine setting, and machining application. This regression 
TABLE 7: MRR, Torque, and Thrust force values for the corresponding input factor.

\begin{tabular}{lcccccc}
\hline Exp. order & Cutting speed $(\mathrm{rpm})$ & Depth of cut $(\mathrm{mm})$ & Type of cutting tool & MRR $\left(\mathrm{mm}^{3} / \mathrm{s}\right)$ & Torque $(\mathrm{nm})$ & Thrust force $(\mathrm{N})$ \\
\hline 1 & 90 & 0.2 & HSST-TiAlN & 4.781 & 0.3924 & 93.2 \\
2 & 90 & 0.4 & HSST & 5.628 & 0.2943 & 78.48 \\
3 & 90 & 0.6 & HSST-TiN & 5.203 & 0.3679 & 103.005 \\
4 & 270 & 0.2 & HSST & 9.111 & 0.3434 & 88.29 \\
5 & 270 & 0.4 & HSST-TiN & 10.453 & 0.4170 & 78.48 \\
6 & 270 & 0.6 & HSST-TiAlN & 12.755 & 0.4415 & 122.63 \\
7 & 450 & 0.2 & HSST-TiN & 18.272 & 0.5396 & 117.72 \\
8 & 450 & 0.4 & HSST-TiAlN & 19.737 & 0.5886 & 176.58 \\
9 & 450 & 0.6 & HSST & 22.222 & 0.4022 \\
\hline
\end{tabular}

equation is used to visualize the output response variation by plotting surface plots in three dimensions using response and contour surface plots by mapping the input process parameter information.

4.1.1. Regression Analysis for MRR (Cutting Speed vs. Depth of $\mathrm{Cut}$ ). The second-order polynomial regression equation to find the MRR is shown in Table 8 by considering the effect of cutting speed and depth of cut. The value of $R^{2}$ represents the randomness in the generated statistical model. This $R^{2}$ value is around 0.9964, representing that the equation is statistically fit with the considered parameter levels of the cutting speed and depth of cut.

The three-dimensional response surface plot shown in Figure 4(a) represents the relation between the response such as MRR and the input process parameters (cutting speed, depth of cut). MRR value is more during machining the AA 2014 material at high cutting speed and depth of cut.

The variation and the values of the MRR are visualized in Figure 4(b). With an increase in cutting speed and depth of cut, the MRR rises steadily.

4.1.2. Regression Analysis for MRR (Cutting Speed vs. Type of Cutting Tool). The second-order polynomial regression value of MRR is given in Table 9. The $R^{2}$ value, in this case, is found to be 0.9656 . This value represents a significant relation between the cutting speed and the cutting tool type impacting the MRR. The equation fits appropriately with the statistical model with a good variation of the output response for the given input process parameters.

The three-dimensional response surface plot shown in Figure 5(a) represents that the MRR increases steeply with the increase in the cutting speed. MRR is more for milling the AA 2014 material using the TiAlN cutting tool. Figure 5(b) shows the two-dimensional contour plot of MRR by varying the process parameters such as cutting speed and Type of cutting tool.

The MRR significantly determines the amount of material removed from the raw material during machining processes. In general, cutting speed has a significant relation in the calculation of MRR. And the results also proved that the MRR is directly proportional to the cutting speed.

4.1.3. Regression Analysis for MRR (Depth of Cut vs. Type of Cutting Tool). The relationship of MRR with the type of
TABLE 8: Regression model and summary results for MRR.

\begin{tabular}{|c|c|}
\hline Model & $\begin{array}{c}\text { MRR }=4.19+0.00039 \text { speed }- \\
2.30 \text { doc }+0.000058 \text { speed }^{*} \\
\text { speed }+3.0 \text { doc }^{*} \text { doc }+0.02450 \\
\text { speed }{ }^{*} \text { doc }\end{array}$ \\
\hline Summary results & $\begin{array}{c}S \text { value } \\
0.652535\end{array}$ \\
\hline
\end{tabular}

cutting tool and depth of cut is given in Table 10. The $R^{2}$ value of 0.8554 represents a less significant impact for milling AA 2014 using the depth of cut and type of cutting tool as the input parameters combination.

The three-dimensional surface plot and the two-dimensional contour plot are shown in Figures 6(a) and 6(b). There is an uneven variation of MRR by varying the depth of cut, and it exhibits more minor surface curve data variation. MRR is less affected by the depth of cut in this study.

The depth of cut results is not statistically significant, but those values significantly impact the machining materials. This process factor has less impact on the selected process parameter over machining AA 2014 material.

4.2. Second-Order Polynomial Regression Analysis for Torque. Torque plays a vital role to predict the power requirement for machining in an efficient manner. This section provides a detailed analysis of Torque based on the forces measured during milling AA 2014 with the coated cutting tools.

4.2.1. Regression Analysis for Torque (Cutting Speed vs. Depth of Cut). The following $R^{2}$ value of 0.8427 in Table 11 represents that the Torque has a moderate impact on the cutting speed and depth of cut.

The three-dimensional surface plot and two-dimensional contour plot are shown in Figures 7(a) and 7(b) respectively. The machining torque increases steeply with the increase in cutting speed. The results show that there is a surge of force at a higher cutting speed. The coating in the tool provides a better solution for milling the AA 2014 irrespective of controlling the depth of cut.

The contour graphs show that the cutting speed has a direct relation with the Torque. The parametric levels for depth of cut in this study are less adversely affecting the machining torque. The following section provides the detailed analysis of Torque by varying the cutting speed and type of coated cutting tools. 
Response surface plot for Material Removal Rate

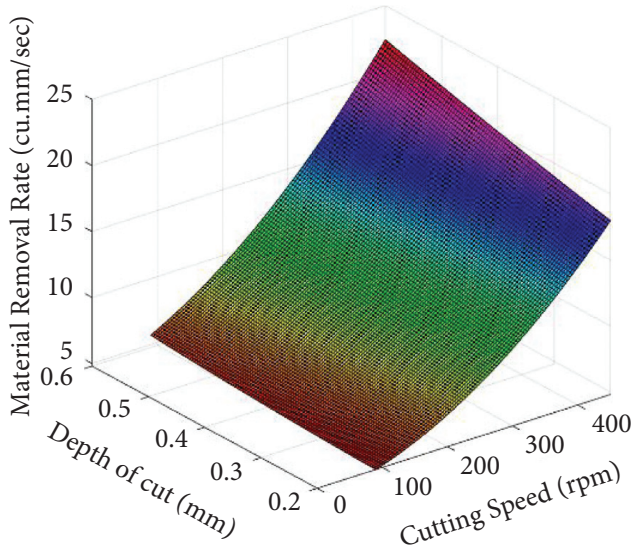

(a)

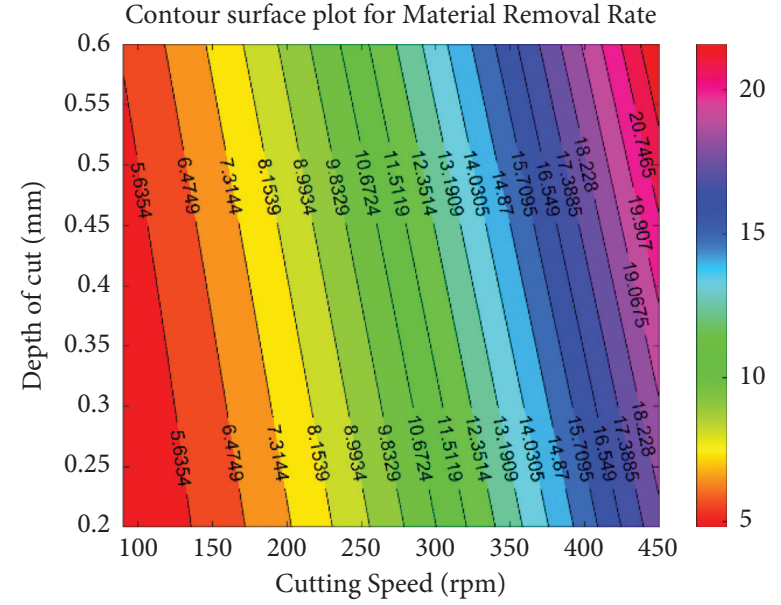

(b)

FIGURE 4: (a)Response surface graph for MRR (cutting speed vs. depth of cut). (b)Contour surface plot for MRR (cutting speed vs. depth of cut).

TABLE 9: Regression model and summary results for MRR.

\begin{tabular}{lc}
\hline Model & $\begin{array}{c}\text { MRR }=6.03+0.0147 \text { speed }-3.59 \text { tool }+0.000058 \text { speed } \\
{ }^{*} \text { speed }+1.06 \text { tool }{ }^{*} \text { tool }-0.00228 \text { speed } * \text { tool }\end{array}$ \\
\hline Summary results & $\begin{array}{c}S \text { value } \\
R^{2} \text { value } \\
0.9656\end{array}$ \\
\hline
\end{tabular}

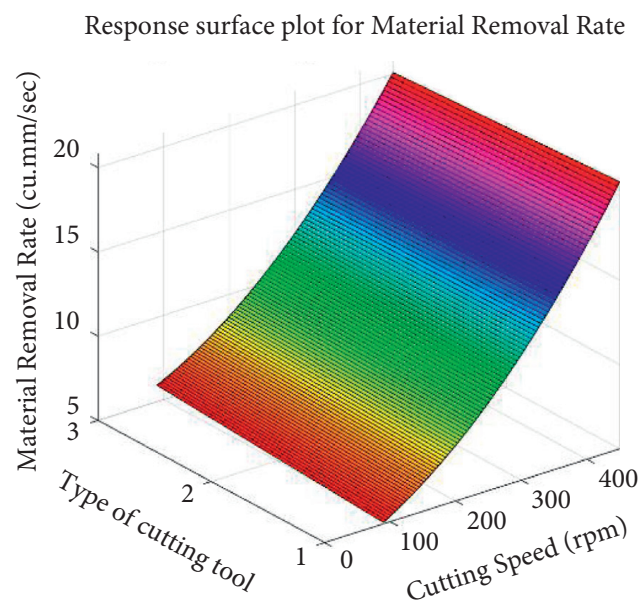

(a)

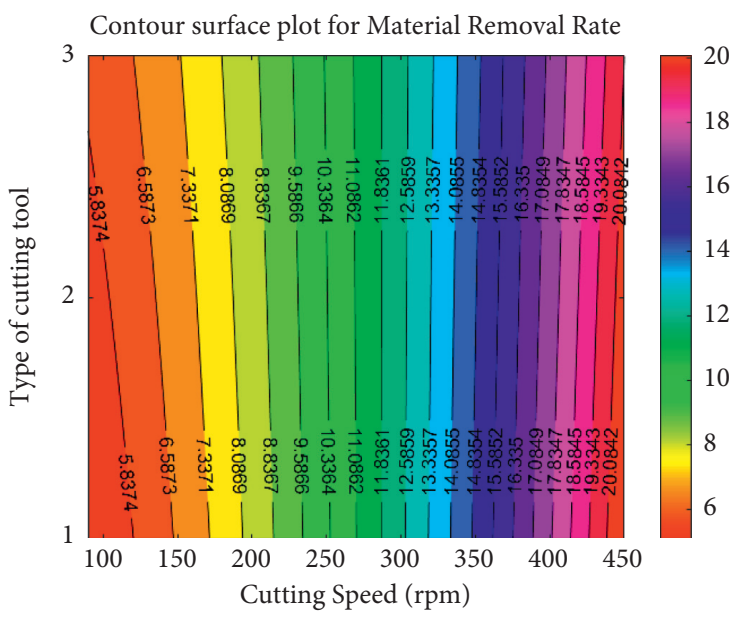

(b)

FIGURE 5: (a)Response surface graph for MRR (cutting speed vs. type of cutting tool). (b)Contour surface plot for MRR (cutting speed vs. type of cutting tool).

TABLE 10: Regression model and summary results for MRR.

\begin{tabular}{|c|c|c|}
\hline Model & & \\
\hline Summary results & $\begin{array}{l}S \text { value } \\
4.5562\end{array}$ & $\begin{array}{c}R^{2} \text { value } \\
0.8554\end{array}$ \\
\hline
\end{tabular}




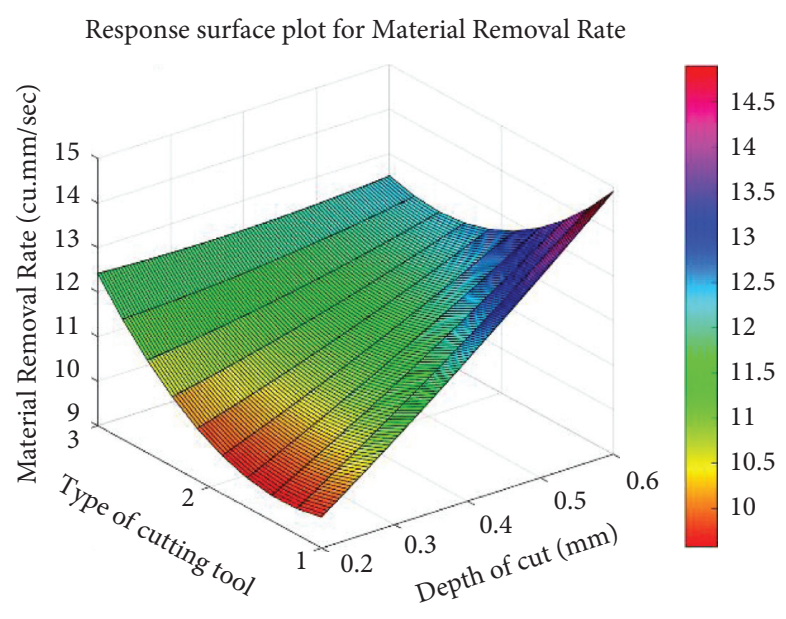

(a)

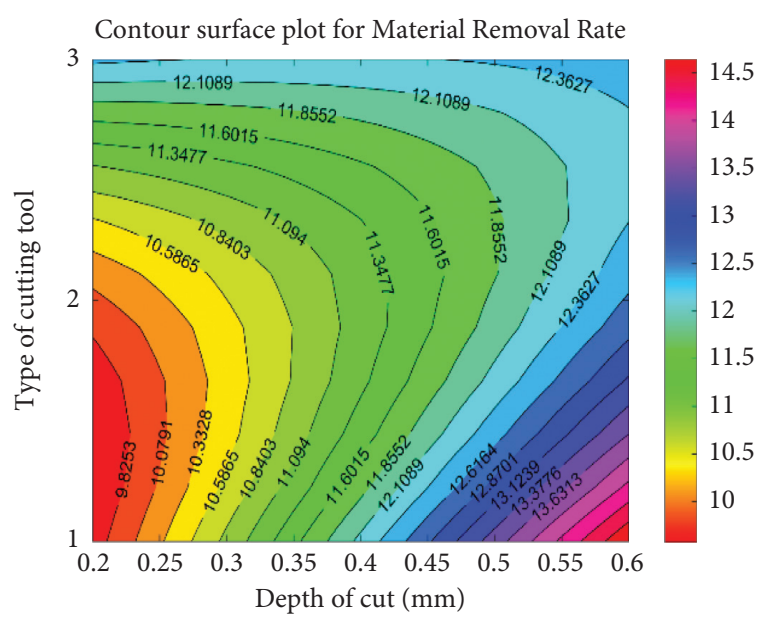

(b)

FIGURE 6: (a)Response surface graph for MRR (type of cutting tool vs. depth of cut). (b)Contour surface plot for MRR (type of cutting tool vs. depth of cut).

TABLE 11: Regression model and summary results for torque.

\begin{tabular}{|c|c|c|}
\hline Model & \multicolumn{2}{|c|}{$\begin{array}{c}\text { Torque }=0.224+0.00025 \text { speed }+0.53 \mathrm{doc}+0.000001 \text { speed } \\
* \text { speed }-0.47 \text { doc }{ }^{*} \text { doc }-0.00078 \text { speed }{ }^{*} \text { doc }\end{array}$} \\
\hline Summary results & $\begin{array}{c}S \text { value } \\
0.0904253\end{array}$ & $\begin{array}{c}R^{2} \text { value } \\
0.8427\end{array}$ \\
\hline
\end{tabular}

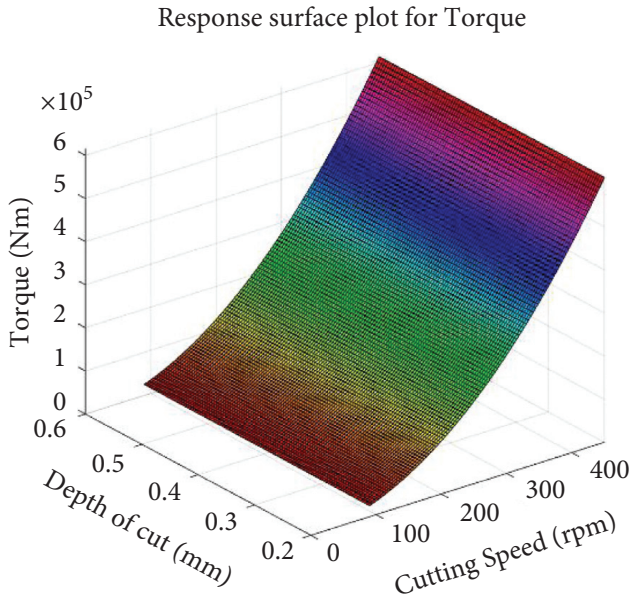

(a)

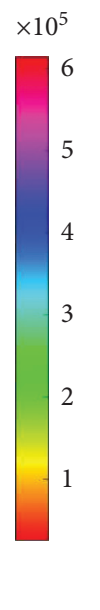

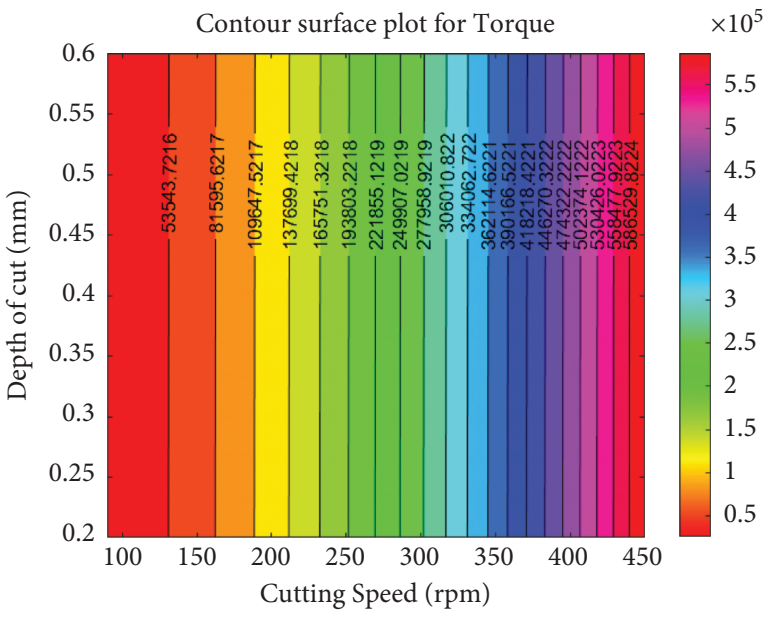

(b)

FiguRE 7: (a)Response surface graph for torque (cutting speed vs. depth of cut). (b)Contour surface plot for torque (cutting speed vs. depth of cut).

4.2.2. Regression Analysis for Torque (Cutting Speed vs. Type of Cutting Tool). The following $R^{2}$ value of 0.9880 in Table 12 represents that the torque impacts the cutting speed and type of cutting tool.

Figures 8(a) and 8(b) depict the three-dimensional surface plot and two-dimensional contour plot, respectively. It was discovered that when the cutting speed increases, the machining torque also increases. The type of cutting tool also plays a vital role in developing the machining torque. The torque value rises steeply for any cutting tool and attains a maximum value of $0.6 \mathrm{Nm}$ at a cutting speed of $450 \mathrm{rpm}$ using the TiAlN coated HSS cutting tool.

\subsubsection{Regression Analysis for Torque (Type of Cutting Tool vs.} Depth of Cut). The following $R^{2}$ value of 0.8040 in Table 13 represents that the Torque has a low impact on the type of cutting tool and depth of cut. 
TABLE 12: Regression model and summary results for Torque.

\begin{tabular}{lcc}
\hline Model & $\begin{array}{c}\text { Torque }=0.1847-0.000308 \text { speed }+0.1551 \text { tool }+0.000001 \text { speed; } \\
* \text { speed }-0.0311 \text { tool * tool }+0.000123 \text { speed } * \text { tool }\end{array}$ \\
\hline Summary results & $S$ value & $R^{2}$ value \\
& 0.0165464 & 0.9880 \\
\hline
\end{tabular}

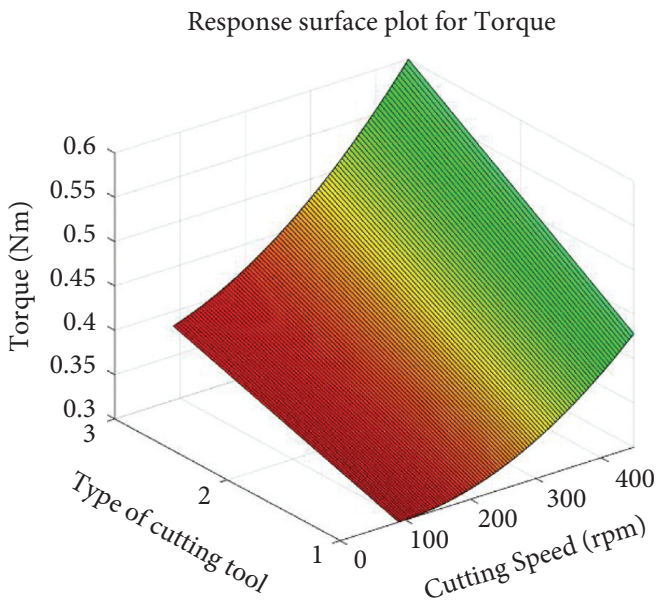

(a)

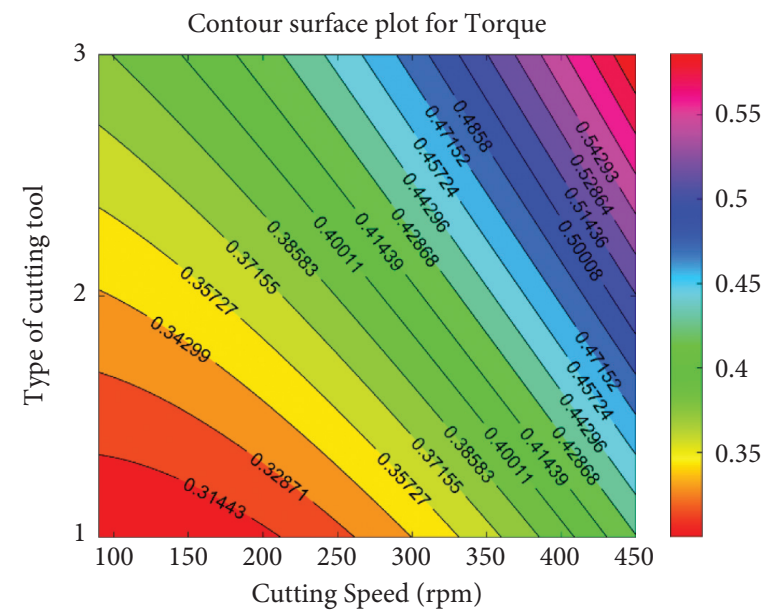

(b)

Figure 8: (a)Response surface graph for Torque (cutting Speed vs. type of cutting tool). (b)Contour surface plot for Torque (cutting Speed vs. type of cutting tool).

TABLE 13: Regression model and summary results for Torque.

\begin{tabular}{lcc}
\hline Model & $\begin{array}{c}\text { Torque }=0.138+0.35 \text { doc }+0.193 \text { tool }-0.47 \text { doc } \\
* \text { doc }-0.0311 \text { tool } \text { tool }^{*} 0.012 \text { doc } * \text { tool }\end{array}$ \\
\hline Summary results & $S$ value & $R^{2}$ value \\
& 0.116786 & 0.8040 \\
\hline
\end{tabular}

The TiN coating enhances the machining torque irrespective of the depth of cut. But TiAlN coating still increases the machining torque resulting in a better milling process.

The response and contour graphs for machining torque by varying the input process parameters such as type of cutting tool and depth of cut are shown in Figures 9(a) and 9(b), respectively. Thrust force is also calculated in the study, and it is used for analyzing the impact of coated cutting tools at higher cutting speeds. The results of the thrust force are discussed in the next section.

4.3. Second-Order Polynomial Regression Analysis for Thrust Force. By managing the tool wear rate, the thrust force controls the tool life of the cutting tool under defined operating conditions. Hence, this response is considered in this study to understand its impact on the coated cutting tools.

4.3.1. Regression Analysis for Thrust Force (Cutting Speed vs. Depth of ( ut). The following $R^{2}$ value of 0.8294 in Table 14 represents that the thrust force moderately impacts the cutting speed and depth of cut. Figures 10(a) and 10(b) show the three-dimensional response surface plot and two-dimensional contour plot, respectively.
It was discovered that as the cutting speed increases, the thrust force also increases. The thrust force increases as the cut depth increases. It was discovered that, with higher cutting speeds and deeper cuts, the maximal value of thrust force was recorded.

4.3.2. Regression Analysis for Thrust Force (Cutting Speed vs. Type of Cutting Tool). The following $R^{2}$ value of 0.8662 in Table 15 represents that the thrust force has a high impact on the cutting speed and cutting tool type.

It is evident from the response plots in Figures 11(a) and 11(b) that the maximum thrust force is obtained using TiAlN coated cutting tool at $450 \mathrm{rpm}$. The milling efficiency is higher, and the tool wear is lower at these controlled process parameters.

4.3.3. Regression Analysis for Thrust Force (Depth of Cut vs. Type of Cutting Tool). The depth of cut considered in this study has the least significant difference to impact the thrust force. The $R^{2}$ value of 0.8303 in Table 16 represents that there will be some additional factors or higher order levels of depth of cut to understand this process parameter study better. 


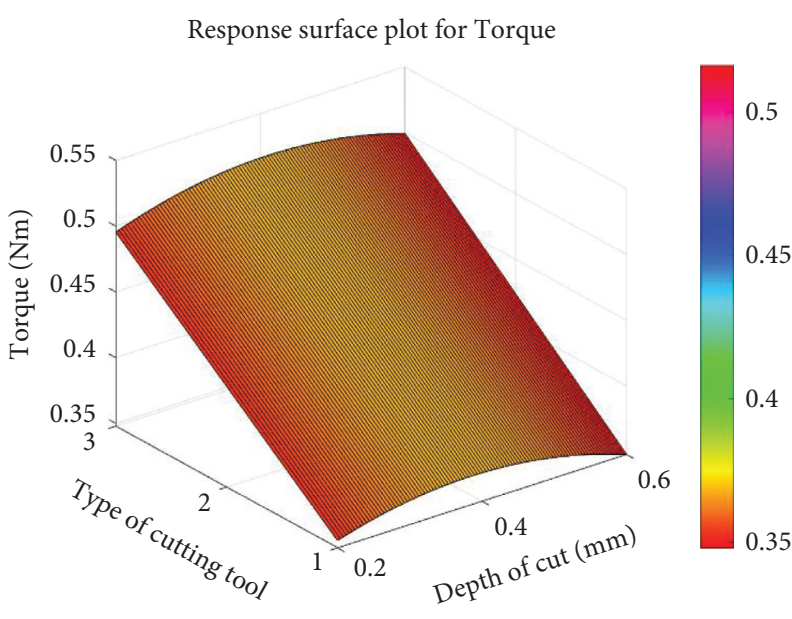

(a)

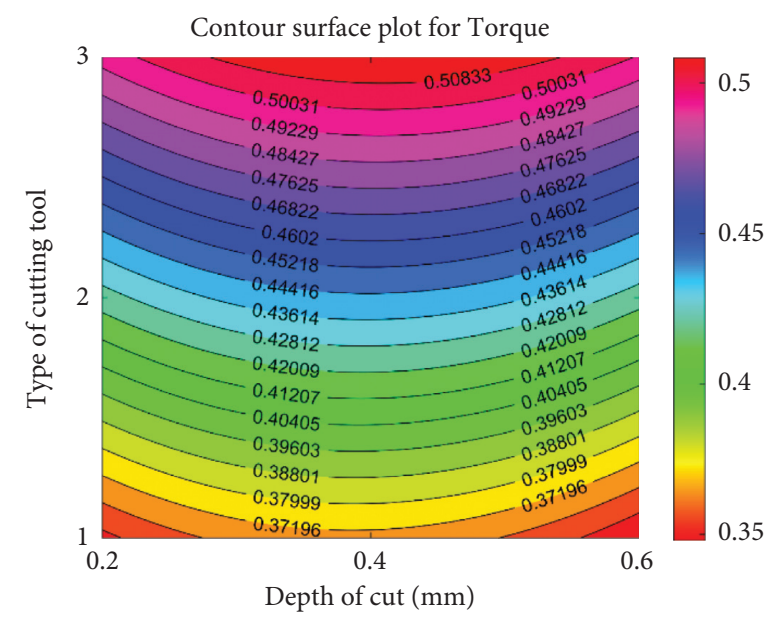

(b)

Figure 9: (a) Response surface graph for Torque (type of cutting tool vs. depth of cut). (b)Contour surface plot for Torque (type of cutting tool vs. depth of cut).

TABLE 14: Regression model and summary results for Thrust force.

\begin{tabular}{|c|c|c|}
\hline Model & \multicolumn{2}{|c|}{$\begin{array}{l}\text { Thrust force }=77.7-0.191 \text { Speed }+94 \text { DOC }+0.000606 \\
\text { Speed }^{*} \text { Speed }-61 \text { DOC }^{*} \text { DOC }+0.000 \text { Speed }{ }^{*} \text { DOC }\end{array}$} \\
\hline Summary results & $\begin{array}{l}S \text { value } \\
30.9372\end{array}$ & $\begin{array}{c}R^{2} \text { value } \\
0.8294\end{array}$ \\
\hline
\end{tabular}

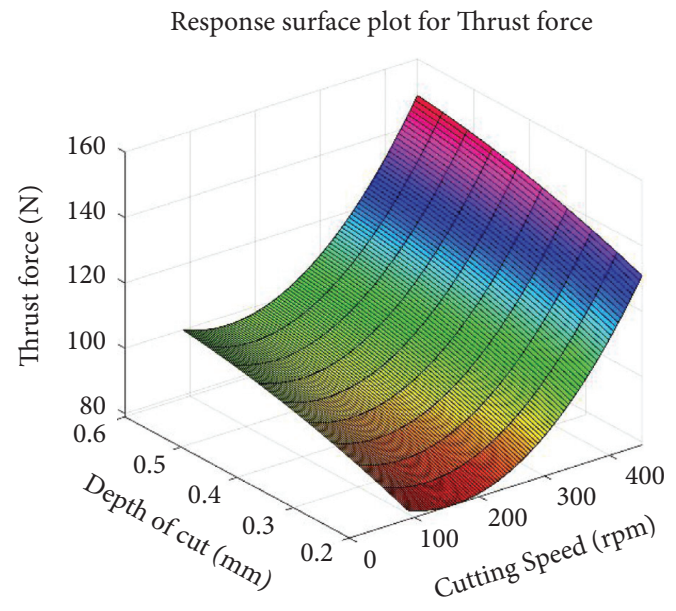

(a)
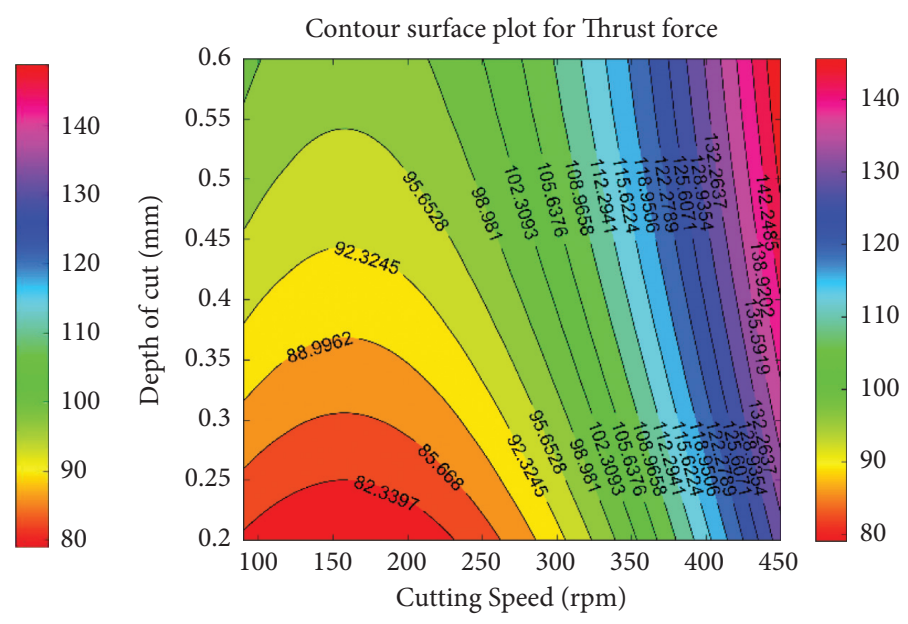

(b)

Figure 10: (a) Response surface graph for Thrust force (depth of cut vs. cutting speed). (b) Contour surface plot for Thrust force (depth of cut vs. cutting speed).

TABLE 15: Regression model and summary results for Thrust force.

\begin{tabular}{|c|c|c|}
\hline Model & \multicolumn{2}{|c|}{$\begin{array}{l}\text { Thrust force }=145.9-0.286 \text { Speed }-55.4 \text { tool }+0.000606 \\
\text { Speed }{ }^{*} \text { Speed }+14.7 \text { tool }^{*} \text { tool }+0.0477 \text { Speed }{ }^{*} \text { tool }\end{array}$} \\
\hline Summary results & $\begin{array}{l}S \text { value } \\
18.5875\end{array}$ & $\begin{array}{c}R^{2} \text { value } \\
0.8662\end{array}$ \\
\hline
\end{tabular}

The response surface plot in Figure 12(a) is almost flat for the depth of cut axis. The thrust force values mentioned in Figure 12(b) show similar near-net values. Thus, there is a most negligible impact on the levels of depth of cut, and its contribution over the output responses is minimal in this study. 


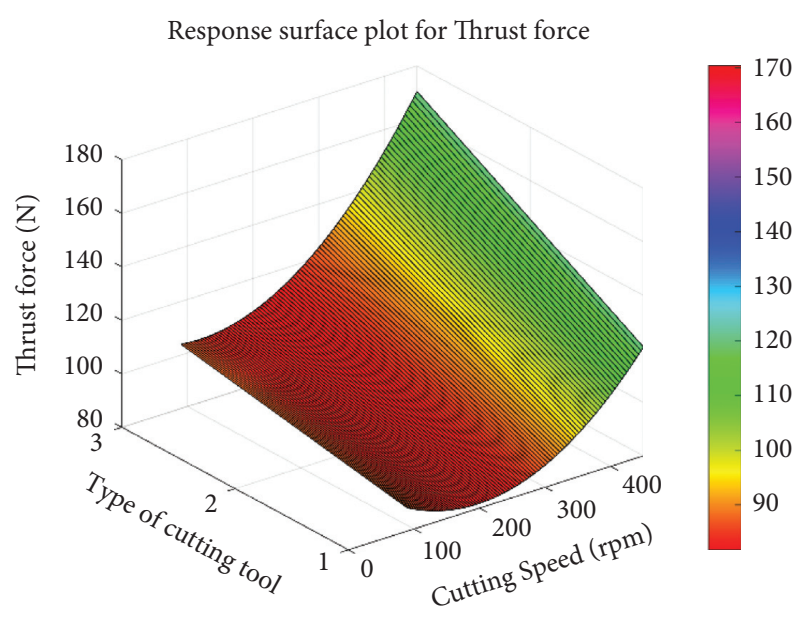

(a)

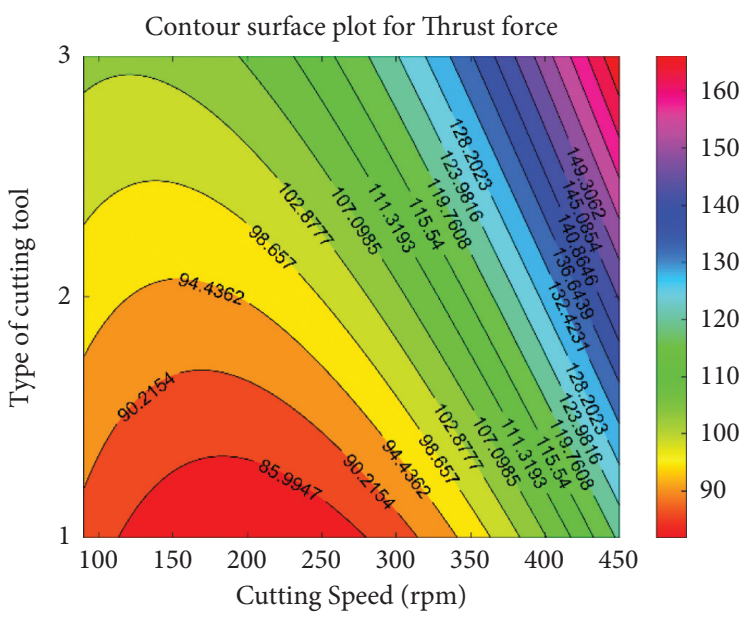

(b)

Figure 11: (a) Response surface plot for Thrust force (cutting tool-type vs. cutting speed). (b) Contour surface plot for Thrust force (cutting tool-type vs. cutting speed).

TABLE 16: Regression model and summary results for Thrust force.

\begin{tabular}{lrr}
\hline Model & & $\begin{array}{c}\text { Thrust force }=90+119 \mathrm{DOC}-38 \text { tool }-61 \mathrm{DOC} \\
* \text { DOC }+14.7 \text { tool } * \text { tool }-12 \mathrm{DOC} * \text { tool }\end{array}$ \\
\hline Summary results & $\begin{array}{c}S \text { value } \\
R^{2} \text { value } \\
0.8303\end{array}$ \\
\hline
\end{tabular}

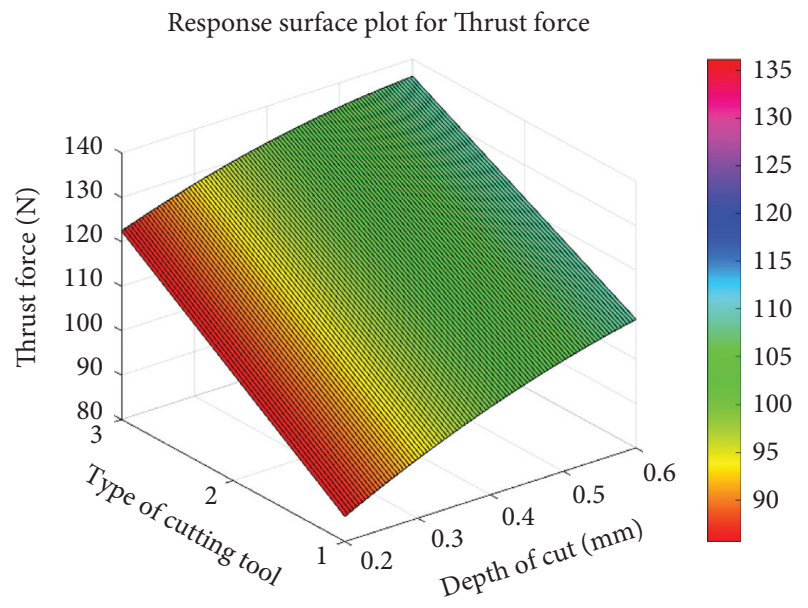

(a)

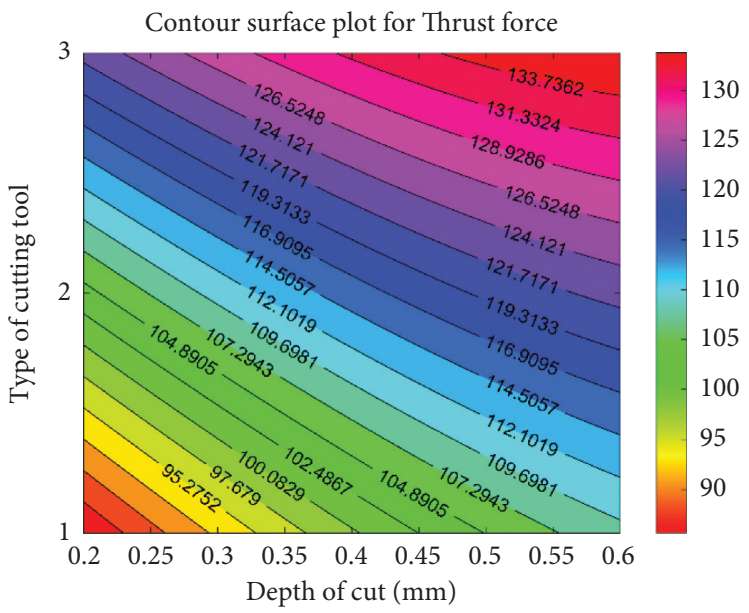

(b)

Figure 12: (a) Response surface plot for Thrust force (depth of cut vs. cutting tool type). (b) Contour surface plot for Thrust force (depth of cut vs. cutting tool type).

4.4. Calculation of GRG Using Grey Relational Analysis. The Signal-to-Noise $(\mathrm{S} / \mathrm{N})$ ratio for MRR, Torque, and Thrust force is calculated using the Larger the Better characteristic. The formula to calculate the $\mathrm{S} / \mathrm{N}$ ratio is given in equation (4) for the output responses.

$$
\frac{S}{N} \text { ratio }=-10 \log _{10}\left(\frac{1}{r} \cdot \sum_{k=1}^{n}\left(\frac{1}{y_{i}}\right)_{k}^{2}\right),
$$

where $y_{i}$ is the measured output response; $r$ represents the experiment replications; $n$ is the number of output responses considered in this study; $n$ is the maximum number of experiments carried out by varying the input process parameters; $k$ is the experimental order value, which ranges from $1,2,3, \ldots n$.

The experimental trials' normalized $\mathrm{S} / \mathrm{N}$ ratio $(\mathrm{Zi})$ values modify the $\mathrm{S} / \mathrm{N}$ ratio values restrained on a separate scale to a standard scale. The normalized $\mathrm{S} / \mathrm{N}$ ratio values are fitted to a 
scale ranging from 0 to 1 . The normalized $\mathrm{S} / \mathrm{N}$ ratio for the larger the better characteristic condition is calculated using

$$
Z_{i}=\frac{y_{i}-\min \left(y_{i}, i=1,2, \ldots, n\right)}{\max \left(y_{i}, i=1,2, \ldots, n\right)-\min \left(y_{i}, i=1,2, \ldots, n\right)} .
$$

These normalized $\mathrm{S} / \mathrm{N}$ ratio values are used to find the relationship from the output responses by calculating the Grey Relational Coefficient (GRC) values, calculated using

$$
\mathrm{GRC}=\frac{\Delta \min +\zeta \Delta \max }{\Delta(i)+\zeta \Delta \max } .
$$

In the above relation, $\Delta \min$ and $\Delta$ max represent the minimum and maximum of the normalized $\mathrm{S} / \mathrm{N}$ ratio, respectively. $\Delta i$ is the normalized $\mathrm{S} / \mathrm{N}$ ratio for the $i^{\text {th }}$ experimental order in the set of executed experiments. The final step is calculating the Grey Relational Grade (GRG) by amalgamating the effect of all the individual measured responses (MRR, Torque, and Thrust force) into a single response. Equation (7) represents the formula to calculate the GRG for the set of experiments:

$$
\mathrm{GRG}_{i}=\frac{1}{m} \sum_{i=1}^{m} \mathrm{GRC}_{i}
$$

where $m$ is the total number of experiments.

The GRG results are used to construct the quadratic polynomial regression equation to map the relationship between the input process parameter and output response. The GRG values provide the quality characteristic for the multiresponse considered in this study. The higher value of GRG represents the experimental order offers more accurate and optimized results for the given input set of process parameters in this study. The calculated GRG values are shown in Table 17 for each set of the input process parameters in the experimental order. These numbers are examined to determine the best set of process parameter combinations for achieving the desired result.

These GRG values represent the output response such as MRR, Torque, and Thrust force into a single value. This data provides the relationship between all the responses over the input process parameter values. Table 18 provides the Analysis of Variance (ANOVA) results for the selected factors and their effect on the interaction between the process parameters combination. The normalized $\mathrm{S} / \mathrm{N}$ ratio is calculated for the eta value of 0.8 . The larger the better characteristic is considered for all output responses considered in this study.

Linear interaction, square interaction, and two-way interaction are considered in this study to understand the impact of the input process parameters over the desired output response. The percentage contribution of the model values for each input process parameter is given in Table 18. The individual factor contribution (linear model) accounts for $97.05 \%$. The cutting speed variation significantly impacts the MRR, and a more significant amount of thrust force is needed to achieve the required machining torque. The coated cutting tool is the second predominant factor, contributing $13.99 \%$ in this process parameter optimization study. The depth of cut values are limited to a minimum value. This work can be extended to study the same milling process parameter setting at a higher depth of cut in the same AA 2014 material.

All the interaction terms (square and 2-way interaction) contribution is minimal, and the F-ratio value represents that these values are less significant in this study. The ANOVA table is calculated for $95 \%$ confidence interval and $5 \%$ significance level for the control factors over the GRG values calculated from the desired output responses. Figure 13 maps the percentage contribution of individual characteristics and their interaction values in the form of a three-dimensional pie-chart.

The variation of GRG values for the $L_{9}$ experimental matrix considered in this study for the corresponding process parameter setting is displayed in Figure 14. These means of the GRG values are analyzed further to find the optimum process parameter setting for milling AA 2014 material using the coated cutting tools.

4.5. Grey Taguchi-Based Response Surface Methodology. The second-order polynomial regression equation is derived to find the GRG values at a particular process parameter setting. Equation (8) shows the final derived result for the input process parameters:

$$
\begin{aligned}
\text { GRG }= & 0.9702-0.001070 \text { Speed }+0.618 \text { DOC } \\
& +0.025 \text { Tool }-0.00 \text { Speed } * \text { Speed } \\
& -1.225 \text { DOC } * \text { DOC }-0.0244 \text { Tool } * \text { Tool } \\
& +0.000756 \text { Speed } * \text { DOC. }
\end{aligned}
$$

The formulated regression equation is statistically fitted with the measured experimental data values. The $R^{2}$ and adjusted $R^{2}$ values are calculated for this derived model to check the efficacy of the proposed GRG polynomial regression equation.

The $R^{2}$ value (0.9970) is of near unity in Table 19 , for the predicted GRG model, representing no intervention of external factors in the fitted model. The adjusted $R^{2}$ value reasonably agrees with the predicted $R^{2}$ value, indicating that the experimental data fit adequately in the proposed secondorder polynomial regression model.

4.5.1. Regression Analysis for GRG (Cutting Speed, Depth of Cut). The GRG model equation is derived for the cutting speed and depth of cut with an $R^{2}$ value of 0.8549 . Table 20 depicts the regression model and the summary results for the input process parameter combination (Cutting speed and Depth of Cut).

This response and contour graph in Figures 15(a) and 15(b) represent the impact of cutting speed and depth of cut over the combined effect of all the measured output responses. Larger depth of cut and higher cutting speed need robust machine structure and holding fixture for proper machining accuracy and better surface finish in the machined parts. The mean range value of cutting speed 
TABLE 17: Calculation of Grey Relational Grade (GRG) values.

\begin{tabular}{|c|c|c|c|c|c|c|c|c|c|c|}
\hline \multirow{2}{*}{ Exp. order } & \multicolumn{3}{|c|}{$\mathrm{S} / \mathrm{N}$ ratio } & \multicolumn{3}{|c|}{ Normalized $\mathrm{S} / \mathrm{N}$ ratio } & \multicolumn{3}{|c|}{ GRC } & \multirow{2}{*}{ GRG } \\
\hline & MRR & Torque & Thrust force & MRR & Torque & Thrust force & MRR & Torque & Thrust force & \\
\hline 1 & 13.5904 & -8.1254 & 39.3883 & 0 & 0.415 & 0.2119 & 1 & 0.6584 & 0.7906 & 0.8163 \\
\hline 2 & 15.0071 & -10.624 & 37.8952 & 0.106 & 0 & 0 & 0.883 & 1 & 1 & 0.961 \\
\hline 3 & 14.3251 & -8.6854 & 40.2572 & 0.055 & 0.322 & 0.3353 & 0.9357 & 0.7129 & 0.7047 & 0.7844 \\
\hline 4 & 19.1913 & -9.2840 & 38.9182 & 0.4197 & 0.223 & 0.1452 & 0.6559 & 0.782 & 0.8464 & 0.7614 \\
\hline 5 & 20.3848 & -7.5973 & 37.8952 & 0.509 & 0.5028 & 0 & 0.6112 & 0.614 & 1 & 0.7417 \\
\hline 6 & 22.1136 & -7.1014 & 41.7719 & 0.639 & 0.585 & 0.5504 & 0.556 & 0.5776 & 0.5924 & 0.5753 \\
\hline 7 & 25.2357 & -5.3586 & 41.4170 & 0.873 & 0.875 & 0.5 & 0.4782 & 0.4776 & 0.6154 & 0.5237 \\
\hline 8 & 25.9056 & -4.6036 & 44.9388 & 0.923 & 1 & 1 & 0.4643 & 0.444 & 0.444 & 0.4508 \\
\hline 9 & 26.9357 & -7.9112 & 42.1122 & 1 & 0.4506 & 0.5987 & 0.444 & 0.6397 & 0.5720 & 0.5519 \\
\hline Min. & 13.5904 & -10.624 & 37.8952 & & & & & & & \\
\hline Max. & 26.9357 & -4.6036 & 44.9388 & & & & & & & \\
\hline Delta & 13.3453 & 6.0206 & 7.0436 & & & & & & & \\
\hline
\end{tabular}

*The larger the better-material removal rate, torque, and thrust force.

TABLE 18: ANOVA to investigate the input factor contribution for milling AA 2014.

\begin{tabular}{|c|c|c|c|c|c|c|c|}
\hline Source & $\mathrm{DF}$ & Adj. SS & Adj. MS & $F$-value & $P$-value & $\%$ contribution & Remarks \\
\hline Model & 7 & 0.222295 & 0.031756 & 47.40 & 0.111 & & \\
\hline Linear & 3 & 0.215735 & 0.071912 & 107.34 & 0.071 & 97.05 & Significant \\
\hline Speed & 1 & 0.178641 & 0.178641 & 266.66 & 0.039 & 80.36 & Significant \\
\hline DOC & 1 & 0.006004 & 0.006004 & 8.96 & 0.205 & 2.70 & Less significant \\
\hline Tool & 1 & 0.031090 & 0.031090 & 46.41 & 0.093 & 13.99 & Significant \\
\hline Square & 3 & 0.005657 & 0.001886 & 2.81 & 0.407 & 2.54 & Insignificant \\
\hline Speed $*$ Speed & 1 & 0.000262 & 0.000262 & 0.39 & 0.644 & 0.118 & Insignificant \\
\hline $\mathrm{DOC}^{*} \mathrm{DOC}$ & 1 & 0.004802 & 0.004802 & 7.17 & 0.228 & 2.16 & Insignificant \\
\hline Tool ${ }^{*}$ Tool & 1 & 0.000593 & 0.000593 & 0.89 & 0.519 & 0.267 & Insignificant \\
\hline 2-Way Interaction & 1 & 0.001480 & 0.001480 & 2.21 & 0.377 & 0.6658 & Insignificant \\
\hline Speed * DOC & 1 & 0.001480 & 0.001480 & 2.21 & 0.377 & 0.6658 & Insignificant \\
\hline Error & 1 & 0.000670 & 0.000670 & & & 0.3 & Insignificant \\
\hline Total & 8 & 0.222965 & & & & & \\
\hline
\end{tabular}

${ }^{*}$ DOC-depth of cut.

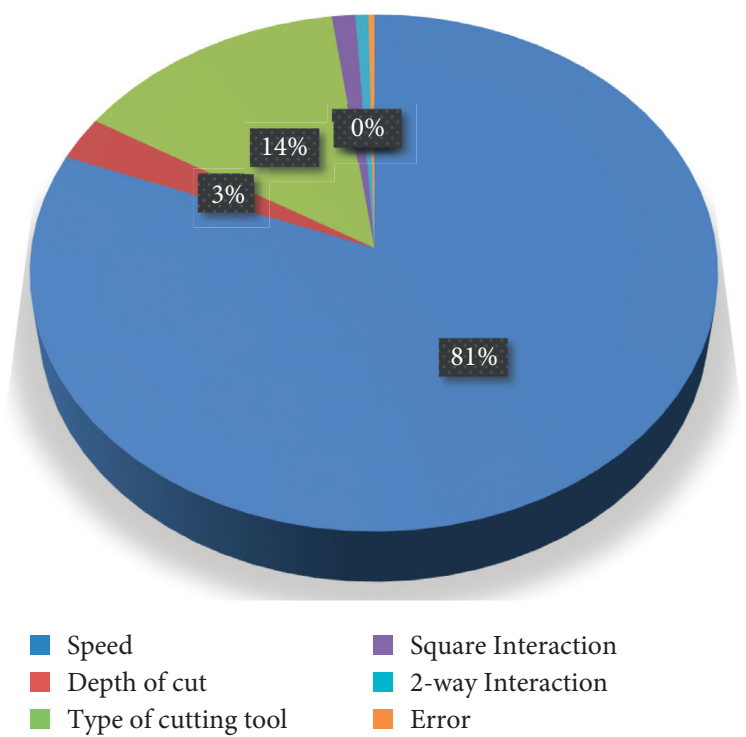

FIGURE 13: Percentage contribution of the input process parameters and their interactions. 


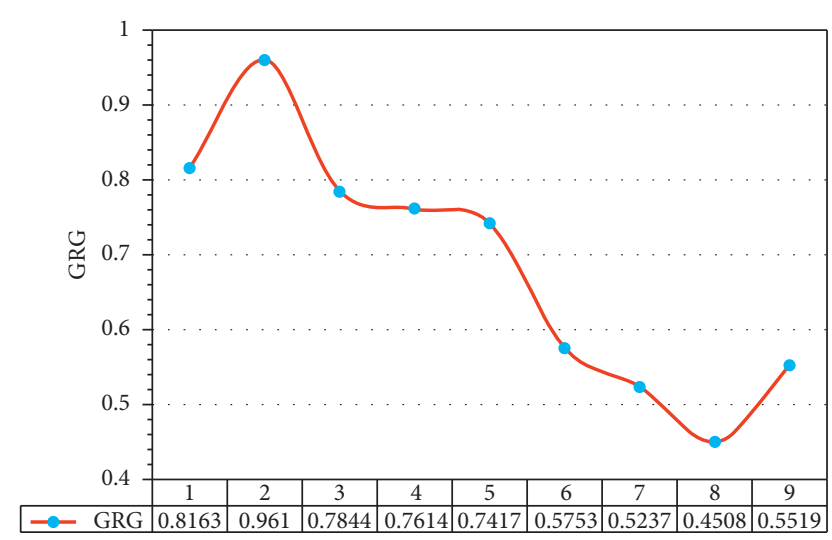

FIGURE 14: GRG values for the corresponding experimental order.

TABle 19: Model summary result.

\begin{tabular}{lcc}
\hline$S$ value & $R^{2}$ value & $R^{2}$ value (adj.) \\
\hline 0.0258829 & 0.9970 & 0.9760 \\
\hline
\end{tabular}

TABLE 20: Regression model and summary results for GRG.

\begin{tabular}{|c|c|}
\hline Model & $\begin{array}{c}\text { GRG }=0.871-0.00093 \text { Speed }+ \\
0.71 \text { DOC }-0.00 \text { Speed } \\
* \text { Speed }-1.22 \\
\text { DOC }{ }^{*} \text { DOC }+0.00042 \\
\text { Speed }{ }^{*} \text { DOC }\end{array}$ \\
\hline Summary results & $\begin{array}{c}S \text { value } \\
0.103847\end{array}$ \\
\hline
\end{tabular}

considered in this study will provide better results in the milled parts of AA 2014 material.

4.5.2. Regression Analysis for GRG (Cutting Speed, Type of Cutting Tool). The $R^{2}$ value $(0.9440)$ is close to unity, which indicates that the cutting speed and the type of cutting tool have a more significant contribution to the output response than DOC values. Table 21 shows the regression model and the fit efficiency test results.

The three-dimensional plot in Figure 16(a) shows a flat plane, where there is a steep and unidirectional variation in the output response for the type of cutting tool and cutting speed. This process parameter combination holds the most significant stake in the output response value.

4.5.3. Regression Analysis for GRG (Type of Cutting Tool, Depth of Cut). The $R^{2}$ value of 0.8891 in Table 22 indicates that the model is statistically fit. There is a possibility that the inclusion of error terms in the model may increase the fit $R^{2}$ value. Since the Aluminum alloy AA 2014 is highly malleable, the cutting tool may plunge quickly into the material resulting in good machinability.

The coated cutting tool with different coating conditions is the second most dominant factor in milling AA 2014 material. The three-dimensional response surface and twodimensional contour plots in Figures 17(a) and 17(b) show a limited variation of the GRG over the change in the DOC values. In addition to these significant parameters, the feed rate is also a parameter considered usually in the machining parameter optimization. This parameter is regarded as a constant in this study to better understand the implications of coated cutting tools. Similarly, there are a lot of external factors affecting the machining of AA 2014 material. Those parameters are considered as residuals or errors in the study. Residual analysis is discussed in the next section, providing a clear-cut idea of the influence of unconsidered process parameters in this experimental study.

4.6. Residual Analysis Study. The residual plots to analyze the error distribution [23] are plotted in Figure 18 as normal probability plot, error fit values, and histogram sorting for the corresponding experimental order considered in this study.

In the main effect plots of Figure 19, the maximum values for each input process parameter (cutting speed, depth of cut, and kind of coated cutting tool) imply a superior process parameter level setting for the relevant factor. But these parameters need to be optimized further by desirability analysis for better-optimized process parameter setting values.

The mean of GRG values is consistently increasing with the increase in the cutting speed, thereby better milling operation at $450 \mathrm{rpm}$ in this study. But the vibration in the structure has a significant impact on the surface roughness in the machined surfaces. The mean GRG values for depth of cut has minor variation, because there is no significant impact at a considered depth of cut parameter level values. The TiAlN coating substantially impacts the considered output responses over the uncoated and TiN coated HSS end mill cutter. The TiAlN coated cutting tool, cutting speed of $450 \mathrm{rpm}$, and depth of cut of $0.6 \mathrm{~mm}$ have the higher mean of GRG values in this process parameter optimization study.

4.7. Predicted vs Actual GRG Values. The regression model is validated by plotting the actual and predicted GRG values using the Design-Expert software (version 13). The closeness in the values is observed at two locations in the graph, as shown in Figure 20. The predicted GRG values are obtained from the polynomial second-order regression equation.

4.8. Process Parameter Optimization Using Desirability Analysis. The desirability analysis test is carried out to predict the optimum input process parameters based on GRG values. Figure 21 shows the overall map of the input process parameter with the desirability and GRG values. The process capability index, $C_{p k}$ function, is used for the predicted GRG values. The process parameter set containing the maximum desirability value is preferred to be the optimal process parameter setting values [24]. The variation of the input factors over the desirability function and predicted GRG values is represented in the form of line graphs.

The ramp function plot in Figure 22 shows the optimized process parameter setting value for the corresponding GRG desirability value. The blue dot in Figure 22 (use web 


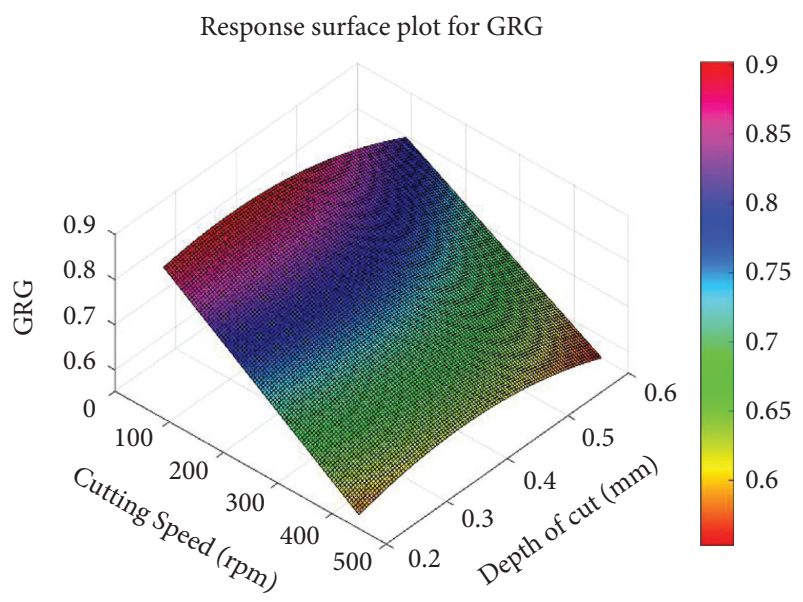

(a)

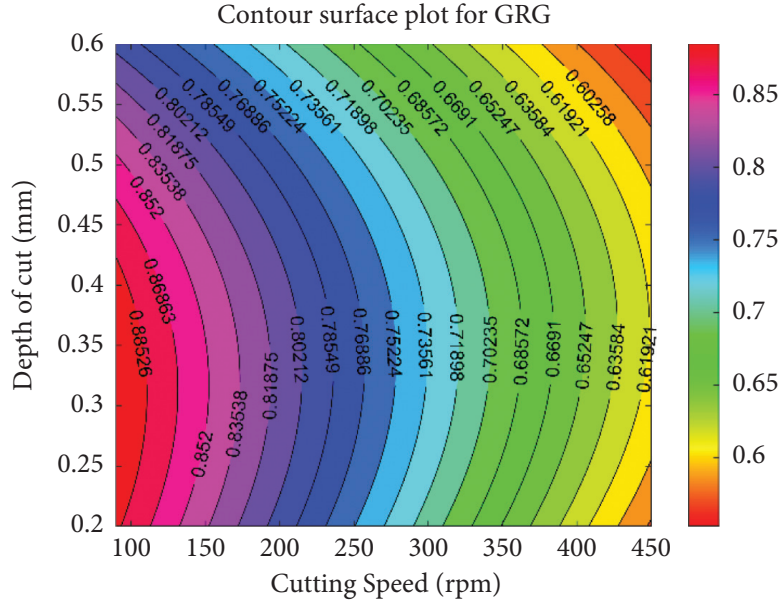

(b)

FIGURE 15: (a) Response surface plot for GRG (cutting speed vs. depth of cut). (b)Contour surface plot for GRG (cutting speed vs. depth of cut).

TABLE 21: Regression model and summary results for GRG.

\begin{tabular}{|c|c|c|}
\hline Model & \multicolumn{2}{|c|}{$\begin{array}{c}\mathrm{GRG}=1.112-0.000889 \text { Speed }-0.100 \text { Tool }-0.00 \text { Speed } \\
{ }^{*} \text { speed }+0.0029 \text { Tool }{ }^{*} \text { tool }+0.000061 \text { Speed }{ }^{*} \text { Tool }\end{array}$} \\
\hline Summary results & $\begin{array}{c}S \text { value } \\
0.0644990\end{array}$ & $\begin{array}{c}R^{2} \text { value } \\
0.9440\end{array}$ \\
\hline
\end{tabular}

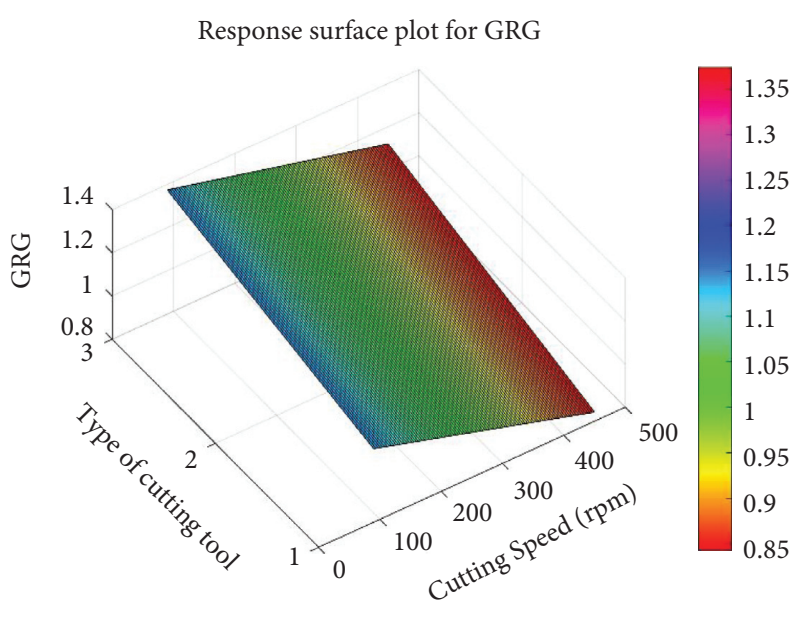

(a)

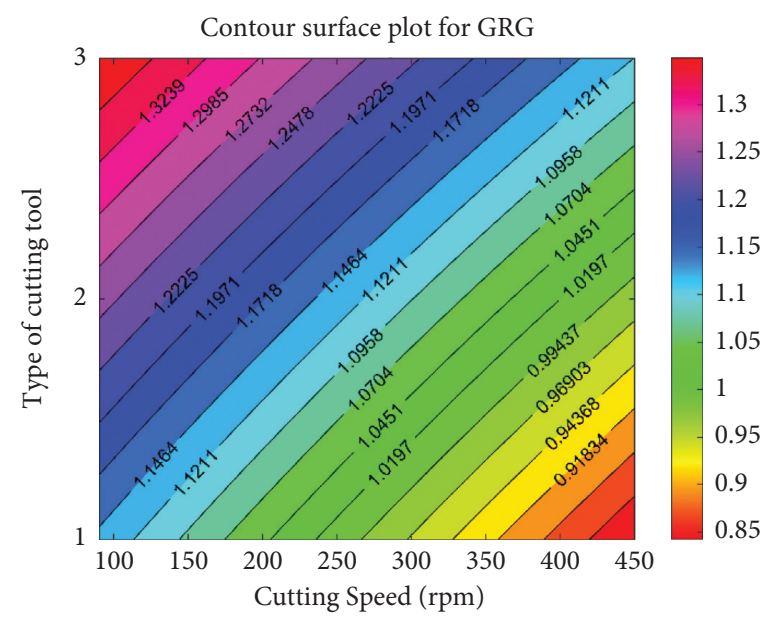

(b)

FIGURE 16: (a) Response surface plot for GRG (cutting speed vs. type of cutting tool). (b) Contour surface plot for GRG (cutting speed vs. type of cutting tool).

TABLE 22: Regression model and summary results for GRG.

\begin{tabular}{lcc}
\hline Model & GRG $=0.707+0.90$ DOC -0.068 Tool -1.22 DOC \\
& & ${ }^{*}$ DOC +0.003 Tool * Tool -0.039 DOC * Tool \\
\hline \multirow{2}{*}{ Summary results } & $S$ value & $R^{2}$ value \\
& 0.245496 & 0.8891 \\
\hline
\end{tabular}




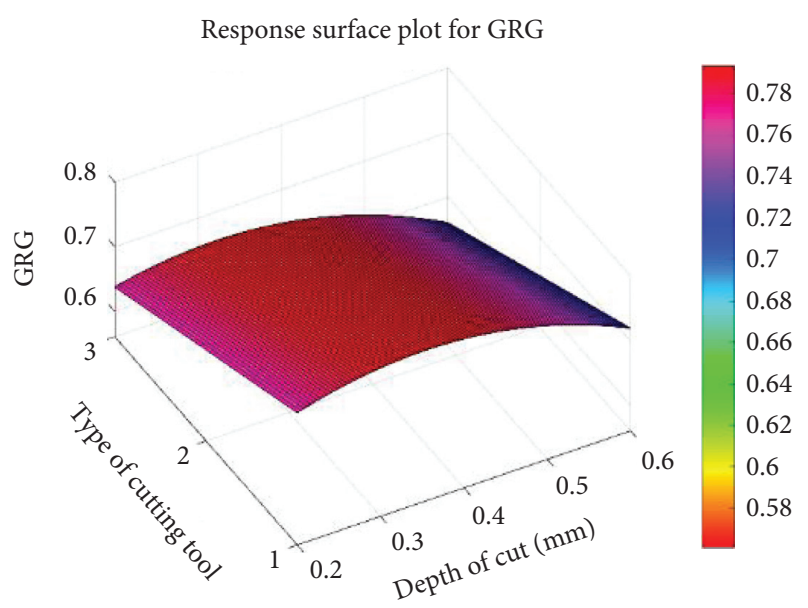

(a)

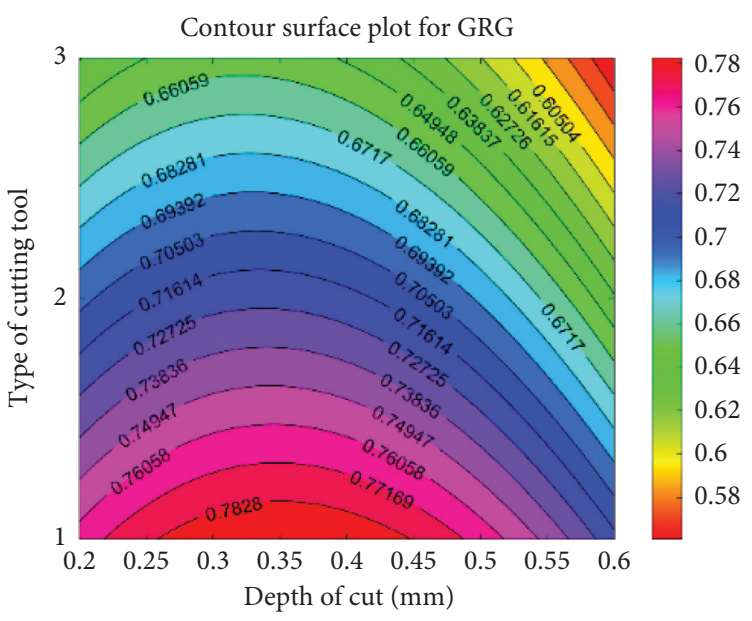

(b)

FIGURE 17: (a) Response surface plot for GRG (depth of cut vs. type of cutting tool). (b) Contour surface plot for GRG (depth of cut vs. type of cutting tool).

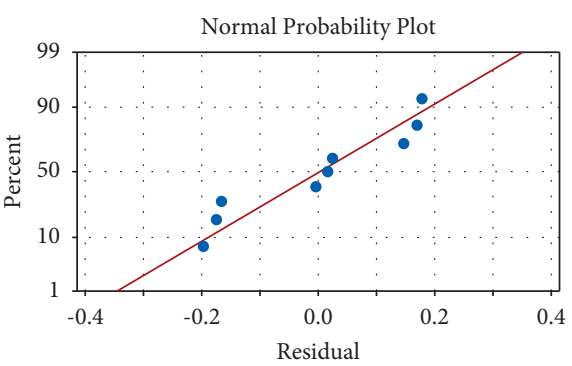

(a)

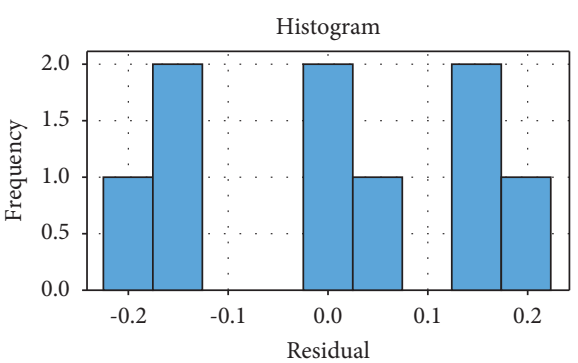

(c)

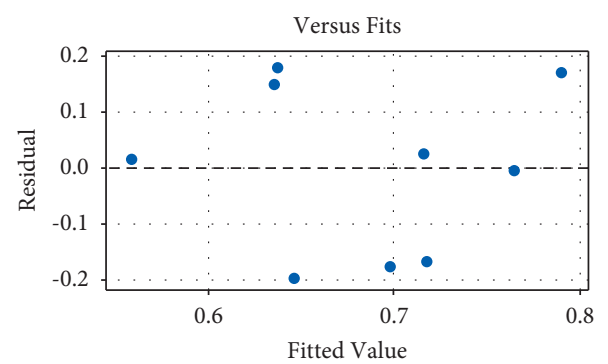

(b)

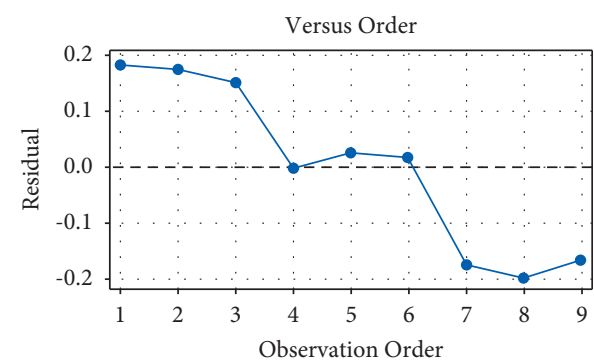

(d)

FIGURE 18: Residual plot analysis for milling AA 2014 material.

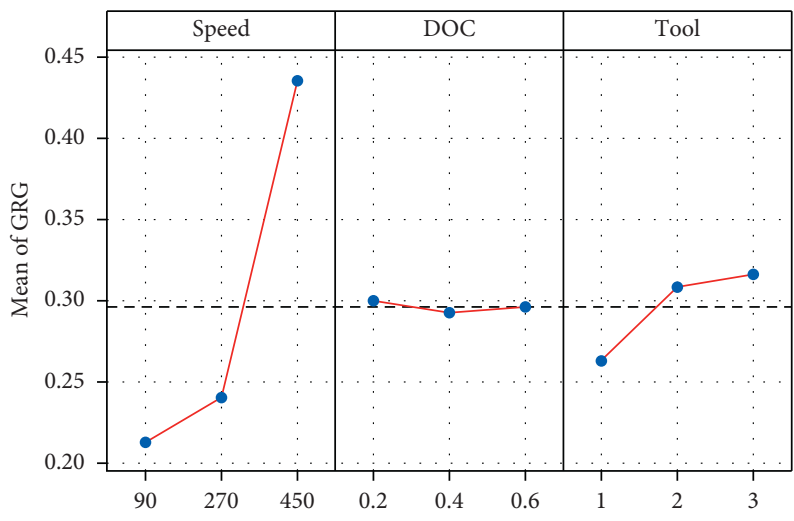

FIGURE 19: Main effect variation plot of GRG values for the process parameters. 


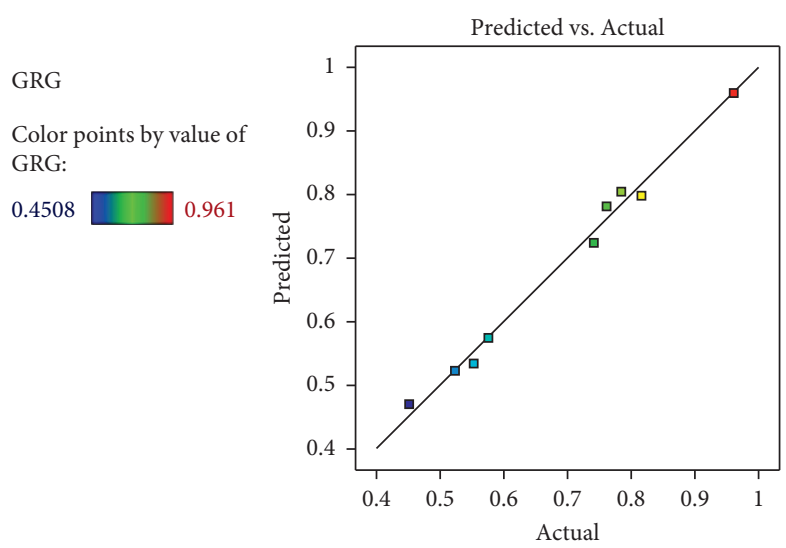

Figure 20: Predicted GRG data vs Actual GRG data.

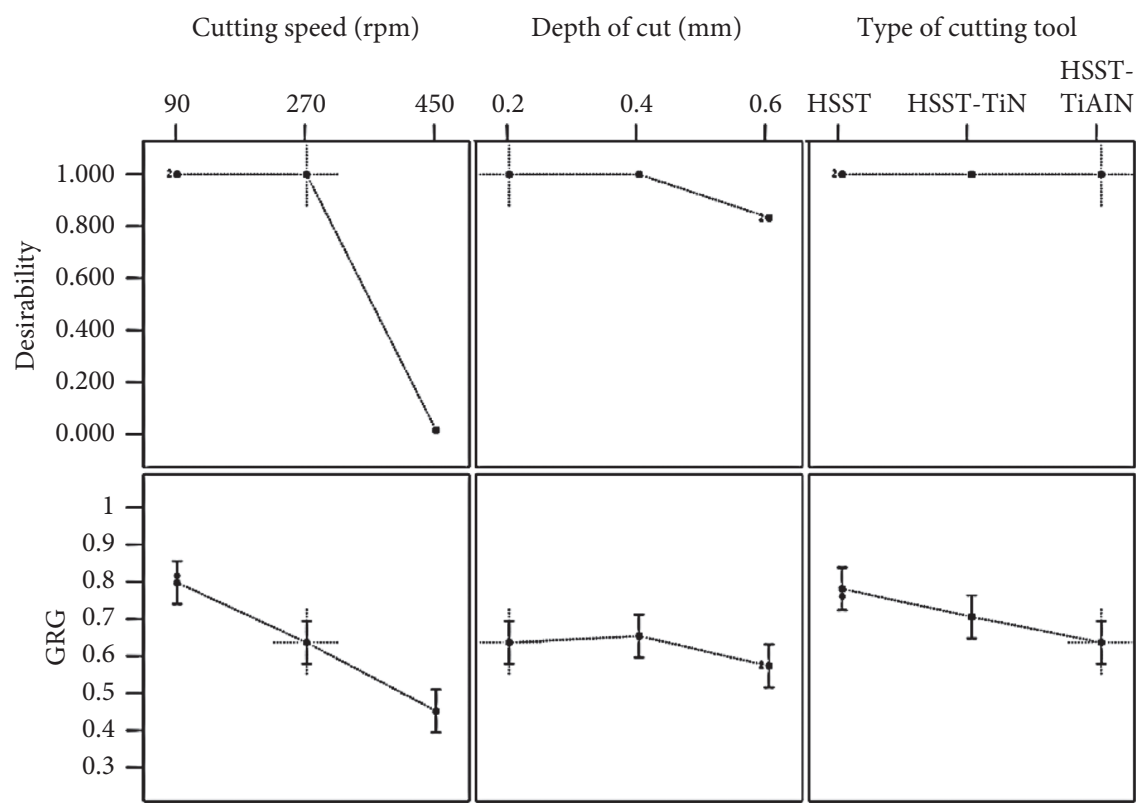

Type of cutting tool : 1-HSST, 2-HSST-TiN, 3-HSST-TiAIN

Figure 21: Desirability analysis result.

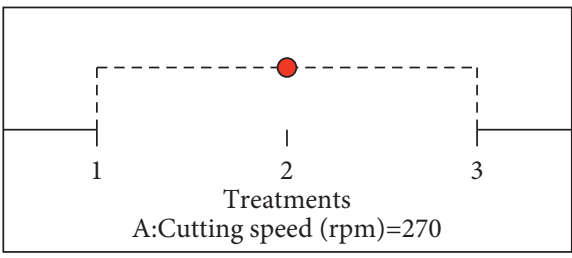

(a)

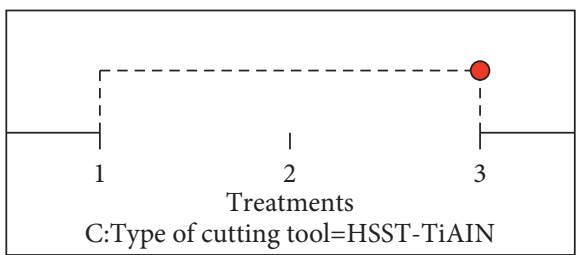

(c)

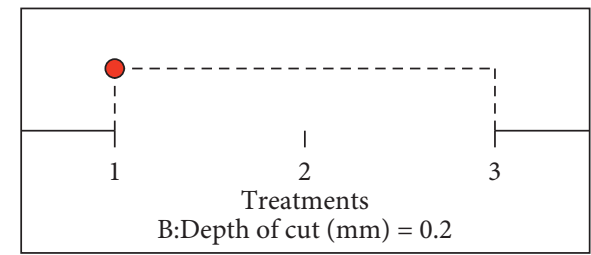

(b)

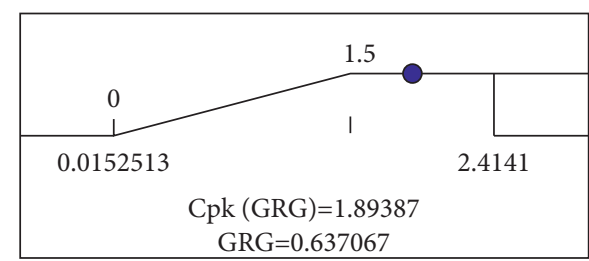

(d)

FIGURE 22: Ramp function graph for desirability analysis. 
version) represents the desired process capability index value (1.89387) with its corresponding GRG value (0.637067).

In accordance with the index value, the optimized process parameters obtained in this study are cutting speed (270 rpm), depth of cut $(0.2 \mathrm{~mm})$, and HSS cutting tool coated with TiAlN material [25]. To validate the results, a confirmation experiment is carried out for this best process parameter combination.

\section{Conclusion}

The impact of TiN and TiAlN coating on the HSS tool was studied by analyzing output response parameters such as MRR, Torque, and Thrust force.

The ANOVA table results show that the cutting speed has $80.36 \%$ contribution, followed by the type of coated cutting tool with $13.99 \%$ contribution. The percentage contribution indicates that the input factor selection and level setting values are correctly designed in this experimental study.

The output response parameters are analyzed using Grey Relational Analysis, and the results are plotted in the form of response surface and contour surface graphs for better visualization.

The process factors such as cutting speed of $270 \mathrm{rpm}$, depth of cut of $0.2 \mathrm{~mm}$, and TiAlN coated HSS cutting tool have the highest process capability index value of 1.89387 and desirability value of 0.637067 . Hence, this process parameter setting is considered the optimized results for milling AA 2014 material in this study.

\section{Data Availability}

The data used to support the findings of this study are included in the article.

\section{Conflicts of Interest}

The authors declare that there are no conflicts of interest regarding the publication of this article.

\section{Acknowledgments}

The authors would like to thank Mr. Parthiban S and Mr. Sarath Kumar R of Saveetha Engineering College, Chennai, for their technical support towards data collection through experimentation. This project was supported by the Deanship of Scientific Research at Prince Sattam bin Abdulaziz University under the research project \# 2020/01/17093.

\section{References}

[1] T. Kollapuri, M. Manoharan, R. B. Sadayan, and R. K. R. Sajja, "A study on the corrosion behaviour of aluminium alloy 2014 T-651 friction stir welds using stress corrosion cracking," Volume 14: Emerging Technologies; Safety Engineering and Risk Analysis; Materials: Genetics to Structures, vol. 14, pp. 1-9, 2015.

[2] Y. Lee, A. Resiga, S. Yi, and C. Wern, "The optimization of machining parameters for milling operations by using the
Nelder-Mead Simplex method," Journal of Manufacturing and Materials Processing, vol. 4, no. 3, pp. 66-22, 2020.

[3] V. S. Devi, B. K. Gnanavel, P. Murthi, and M. Madhanagopal, "Investigation of novel sustainable concrete using optimization technique," Advanced Materials Proceedings, vol. 2, no. 2, pp. 86-92, 2017.

[4] K. Senthilkumaran, P. M. Pandey, and P. V. M. Rao, "Statistical modeling and minimization of form error in SLS prototyping," Rapid Prototyping Journal, vol. 18, no. 1, pp. 38-48, 2012.

[5] L. M. Maiyar, R. Ramanujam, K. Venkatesan, and J. Jerald, "Optimization of machining parameters for end milling of Inconel 718 super alloy using Taguchi based grey relational analysis," Procedia Engineering, vol. 64, pp. 1276-1282, 2013.

[6] B. Das, S. Roy, R. N. Rai, and S. C. Saha, "Application of grey fuzzy logic for the optimization of CNC milling parameters for $\mathrm{Al}-4.5 \% \mathrm{Cu}-\mathrm{TiC} \mathrm{MMCs}$ with multi-performance characteristics," Eng. Sci. Technol. an Int. J.vol. 19, no. 2, pp. 857-865, 2016.

[7] M. N. Durakbasa, A. Akdogan, A. S. Vanli, and A. G. Bulutsuz, "Optimization of end milling parameters and determination of the effects of edge profile for high surface quality of AISI H13 steel by using precise and fast measurements," Measurement, vol. 68, pp. 92-99, 2015.

[8] H. S. Lu, C. K. Chang, N. C. Hwang, and C. T. Chung, "Grey relational analysis coupled with principal component analysis for optimization design of the cutting parameters in highspeed end milling," Journal of Materials Processing Technology, vol. 209, no. 8, pp. 3808-3817, 2009.

[9] S. R. Elsen, K. Dhamodaran, and J. R. Aseer, "Multi-objective optimization of end milling process parameter for stir casted alumina reinforced aluminium metal matrix composite using RSM," IOP Conference Series: Materials Science and Engineering, vol. 402, no. 1, Article ID 012193, 2018.

[10] J. H. Shaik and J. Srinivas, "Optimal selection of operating parameters in end milling of Al-6061 work materials using multi-objective approach," Mech. Adv. Mater. Mod. Process.vol. 3, no. 1, 2017.

[11] J. Ren, J. Zhou, and J. Wei, “Optimization of cutter geometric parameters in end milling of titanium alloy using the greytaguchi method," Advances in Mechanical Engineering, vol. 7, no. 2,2015

[12] R. Adalarasan, M. Santhanakumar, and M. Rajmohan, “Application of Grey Taguchi-based response surface methodology (GT-RSM) for optimizing the plasma arc cutting parameters of 304L stainless steel," International Journal of Advanced Manufacturing Technology, vol. 78, no. 5-8, pp. 1161-1170, 2015.

[13] J. Xu, F. Yan, Y. Li, Z. Yang, and L. Li, "Multiobjective optimization of milling parameters for ultrahigh-strength steel AF1410 based on the NSGA-II method," Annals of Materials Science \& Engineering, vol. 2020, Article ID 8796738, 11 pages, 2020.

[14] R. Adalarasan, M. Santhanakumar, and A. Shanmuga Sundaram, "Optimization of weld characteristics of friction welded AA 6061-AA 6351 joints using grey-principal component analysis (G-PCA)," Journal of Mechanical Science and Technology, vol. 28, no. 1, pp. 301-307, 2014.

[15] R. J. P. S. K. Krishnaiah, "Quality management research by considering multi-response problems in the Taguchi method - a review," Journal of Advanced Manufacturing Technology, vol. 26, pp. 1331-1337, 2005.

[16] A. Tamadon, D. J. Pons, K. Sued, and D. Clucas, "Development of metallographic etchants for the microstructure 
evolution of A6082-t6 BFSW welds," Metals, vol. 7, p. 10, 2017.

[17] S. P. Dwivedi, S. Sharma, and R. K. Mishra, "Mechanical and metallurgical characterizations of AA2014/eggshells waste particulate metal matrix composite," Int. J. Precis. Eng. Manuf. - Green Technol.vol. 3, no. 3, pp. 281-288, 2016.

[18] S. R. K. Rao, G. M. Reddy, and K. P. Rao, "Effects of thermomechanical treatments on mechanical properties of AA2219 gas tungsten arc welds," Journal of Materials Processing Technology, vol. 202, no. 1-3, pp. 283-289, 2008.

[19] R. E. Smallman and A. H. W. Ngan, "Characterization and analysis,” Mod. Phys. Metall., pp. 159-250, 2014.

[20] A. Kulandaivel and S. K. Santhanam, "Experimental investigation on turning of monel K500 alloy using nano graphene cutting fluid under minimum quantity lubrication," in Proceedings of the 2019 International Mechanical Engineering Congress and Exposition, Nov 2019.

[21] A. Kulandaivel and S. Kumar, "Effect of magneto rheological minimum quantity lubrication on machinability, wettability and tribological behavior in turning of Monel K500 alloy," Machining Science and Technology, vol. 24, no. 5, pp. 810-836, 2020.

[22] Y. Sesharao, T. Sathish, P. Kumaran et al., "Optimization on operation parameters in reinforced metal matrix of AA6066 composite with HSS and Cu," Annals of Materials Science \& Engineering, vol. 2021, Article ID 1609769, 12 pages, 2021.

[23] T. Sathish, S. Tharmalingam, V. Mohanavel et al., "Weldability investigation and optimization of process variables for TIG-welded aluminium alloy (AA 8006)," Annals of Materials Science \& Engineering, vol. 2021, Article ID 2816338, 17 pages, 2021.

[24] S. Gopalakannan and T. Senthilvelan, "Application of response surface method on machining of Al-SiC nano-composites," Meas. J. Int. Meas. Confed.vol. 46, no. 8, pp. 2705-2715, 2013.

[25] K. Arul and S. Kumar, "Magnetorhelogical based minimum quantity lubrication (MR-MQL) with additive n-CuO," Materials and Manufacturing Processes, vol. 35, no. 4, pp. 404-414, 2020. 